\title{
Sobre el arcaísmo de la cerámica rifeña
}

\section{About Archaism of Rif Pottery}

María José Matos Wagner

Investigadora en etnología, arqueología y cerámica, Castellón (España)

marijomatos@gmail.com

\section{Jorge Wagner}

Investigador en arqueología y cerámica, Castellón (España)

jorgewagner04@gmail.com

\author{
ALFARERÍA POPULAR, LA MEMORIA EN LAS MANOS \\ MONOGRÁFICO COORDINADO POR ELENA FREIRE PAZ (Universidad de Santiago de Compostela)
}

\section{RESUMEN}

En este trabajo llamamos la atención ante el llamativo arcaísmo y pervivencia de una cerámica, que, aunque en la actualidad está prácticamente fuera de uso, aunque no desaparecida, estuvo viva y usada hasta bien entrada la segunda mitad del pasado siglo XX. Denominamos rifeña a una cerámica de características muy particulares que se produce en el norte de Marruecos a todo lo largo de la cadena montañosa del Rif en sus dos vertientes y contrafuertes. Esta cordillera discurre paralela a la costa mediterránea. Es la cerámica de uso común en el mundo rural en todo este territorio cubriendo todas sus necesidades y es realizada exclusivamente por mujeres en todas sus fases de producción. En su fabricación no utilizan el torno ni es cocida en los hornos de cerámica tradicionales de cámara, es modelada a mano y cocida en el suelo en primitivas horneras a cielo abierto. Otra de sus características es la variada y rica decoración de sus vasijas con signos cargados de una fuerte simbología.

\section{ABSTRACT}

In this paper we aim to draw attention to the striking archaism and survival of a ceramic which, despite being practically abandoned today, but not extinct, it has been alive and in use until late in the second half of the 20th Century. We call Rifian a type of pottery with very particular characteristics produced in Northern Morocco, along the entire length of the Rif mountain range on its two faces and foothills. This mountain range runs parallel to the Mediterranean coast. This is the pottery most commonly used in the rural areas throughout the region, covering all household and work needs, and is made exclusively by women at all stages of production. It is neither manufacturated using a potter's wheel, nor cooked in traditional pottery kilns, but is hand-modelled and cooked on the ground in primitive open-air kilns. Another of its characteristics is the highly varied and rich decoration of its vessels with signs full of strong symbolism.

PALABRAS CLAVE

El Rif | cerámica rifeña | alfarería femenina | arcaísmo | simbología

KEYWORDS

El Rif | pottery berber | feminine ceramics | archaism | symbology

\section{Introducción}

Las observaciones que recogemos en este texto son fruto de doce años de trabajo de campo realizado al Rif desde 1990 a 2002. En este periodo realizamos un inventario de las cerámicas rifeñas y un censoencuesta de las alfareras que quedaban en activo, hay que tener en cuenta que en el Rif tradicionalmente estas mujeres alfareras no hacen su trabajo de alfarería de forma profesional sino de forma eventual, cuando tenían alguna necesidad para reponer alguna pieza rota o algún encargo, compaginando este trabajo con el resto de faenas de la mujer del campo, cuidar del hogar, de los hijos, ir a por agua a la fuente, recoger hierba para los animales, ayudar en la siega, etc.

Durante estos años de trabajo de campo recogimos tanto cerámicas ya fuera de uso y abandonadas, como las que estaban en pleno uso, en aldeas y aduares, la mayor parte de ellos de difícil acceso, sin agua corriente ni electricidad, con caminos que según la época del año, tenían solo acceso a pie o a lomo de caballería y con el resultado de este trabajo realizamos una exposición en el Museo Nacional de Cerámica González Martí de Valencia y editamos el libro catálogo con el título Cerámica rifeña, el barro femenino.

El hecho de no estar integrados en la academia no ha dotado a nuestro trabajo de las herramientas 
metodológicas propias del análisis antropológico y, sin embargo, tanto el volumen de datos obtenido como el corte temporal en el que se ha realizado el trabajo de campo aseguran la importancia de la información recogida en el presente texto. De nuestro interés, en perspectiva comparativa, por entender la pervivencia de la cerámica en la zona ha derivado la prospección en el arcaísmo de unas formas y motivos que semejan permanecer inalterados desde hace siglos pero que mantienen su presencia en el mundo actual.

\section{Orígenes y desarrollo de las formas de cerámica rifeñas}

El testimonio más antiguo de la presencia de cerámica en el norte de Marruecos lo dan unos restos encontrados en las excavaciones del abrigo de Hassi Ouenzga situado a unos $50 \mathrm{Km}$. al sur de Nador en la comuna de Saka. En sus capas más inferiores da un tipo de cerámica datada sobre 6.000 años a. C. lo que la situaría como anterior a la cerámica cardial. Esta cerámica neolítica con un origen probable en la península ibérica está decorada con motivos reticulados incisos y decoración excisa a base de añadidos plásticos, sus formas son variadas y su base generalmente cónica.

Posteriormente, el conjunto de grutas de Achakar y El Khril cerca de Tánger, el yacimiento de Gar Cahal cerca de Ceuta y en el de Caf That El Gar cerca de Tetuán aparecen en los estratos más antiguos cerámicas decoradas con la impronta que deja el borde de una concha de un molusco bivalvo llamado Cardium Edule. Esta técnica de decoración, llamada cardial, es característica común de los niveles más antiguos del neolítico de todo el Mediterráneo occidental y en el norte del Magreb perdura a lo largo de todo el neolítico llegando hasta poco antes del siglo III a. C. donde aparece esta decoración sobre cerámica doméstica local en yacimientos de época Púnica.

En la actualidad las mujeres alfareras de la localidad de Ifran Alí, pertenecientes a la tribu de los Beni Said en la provincia de Tetuán, no lejos de estos yacimientos, han seguido utilizando la impronta cardial en la decoración de sus vasijas, si bien últimamente han sustituido la concha del cardium edule, por una ruedecilla metálica, pero con el mismo efecto estético.

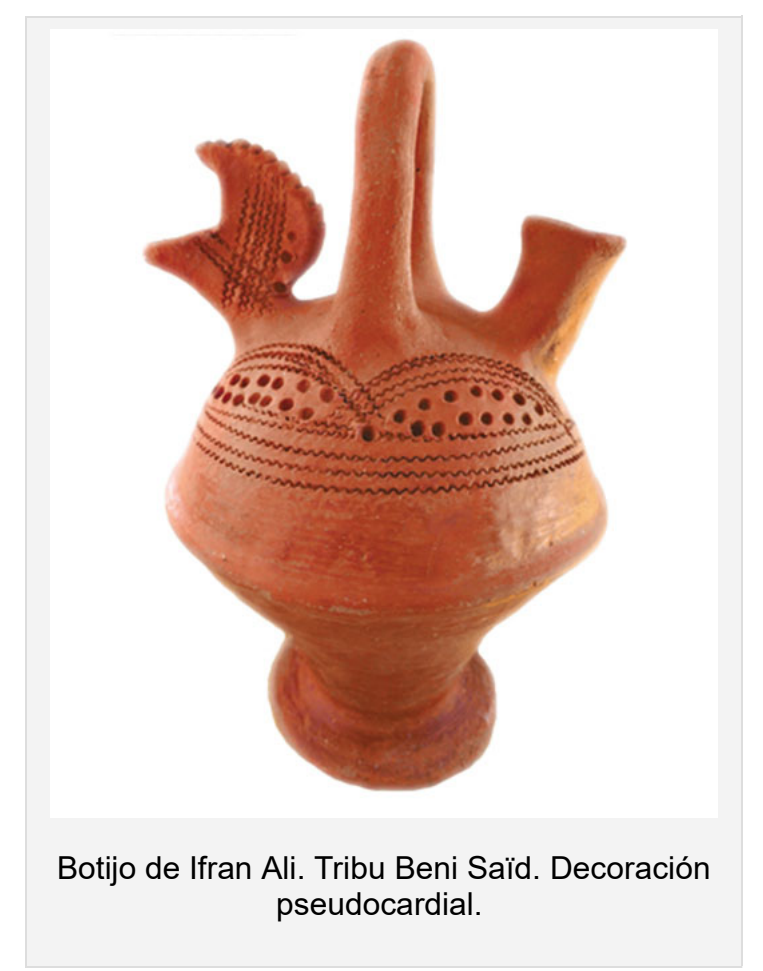

En cuanto al origen de las formas de las cerámicas rifeñas, vemos que la propia técnica de su fabricación, modeladas sin torno, bruñidas y cocidas en horneras a cielo abierto, condicionan ya de por sí unas formas concretas y se puede apreciar la gran similitud, sin entrar en la posibilidad de la influencia o la convergencia cultural, entre algunas cerámicas actuales de las tribus de la costa de la vertiente norte del Rif y las antiguas de sus vecinas del otro lado del Mediterráneo, en concreto con las de la cultura del Argar y las del bronce valenciano. 
Si bien el torno era ya utilizado en el antiguo Egipto desde hace alrededor de 2.400 años a. C. cómo se puede apreciar en algunos bajorrelieves en la tumba de Ty en Saqqara, parece ser, y así está considerado, que fueron los fenicios los que lo introdujeron en el Mediterráneo occidental. Estos navegantes comerciantes en su expansión hacia el oeste a principio del último milenio a. C. y sistemáticamente a partir del siglo VII a. C., fueron creando factorías a lo largo de la costa de ambos lados del estrecho, traspasando las columnas de Hércules fundaron Gadir (Cádiz), siguieron contorneando la costa africana hacia el sur y fundaron Lixus (Larache) llegando hasta la isla de Mogador en Essaouira. Entre estos relativamente importantes centros, crearon una serie de pequeños asentamientos intermedios Sala (Salé), Banasa y Thamusida en la desembocadura del río Sebú, Zilis (Arcila) y en la costa mediterránea Rusadir en Melilla. Esta técnica alfarera se generalizará posteriormente cuando estos centros pasan al poder púnico y con la profunda colonización cartaginesa de todo el norte de África. El uso del torno posteriormente continuará ininterrumpidamente con la colonización romana, visigoda, bizantina y árabe hasta nuestros días.

Normalmente ocurre que cuando una cultura de tecnología superior, como es la utilización del torno y el horno de cámara, que aporta un avance y calidad en la cerámica, se superpone con otra inferior más primitiva y de menor calidad, terminará por suprimirla, tal como ocurrió con la cerámica modelada ibérica en contacto con los colonizadores griegos y la cerámica modelada norteafricana en contacto con la colonización fenicio-púnica. Solamente en las cadenas montañosas del norte de África en concreto las abruptas y escarpadas costas del Rif, con escasos abrigos para la navegación, hizo que la colonización se sintiera con casi nula intensidad. El marcado carácter independiente bereber de sus habitantes tanto en hombres como en mujeres y sobre todo de estas mujeres alfareras que no solamente modelaba las vasijas para satisfacer las necesidades de su tribu, sino que eran conscientes que esta alfarería heredada de madres a hijas desde tiempos inmemorable era un legado con un marcado sello cultural de identidad. Era un deber de las mujeres y nunca dejarían por sus marcados caracteres tribales esta labor en manos de los hombres. Por este motivo llegó y sobrevivió esta alfarería femenina rifeña de modelado a mano y cocción en horneras a cielo abierto que poco ha variado desde las primitivas vasijas neolíticas hasta el final del siglo XX con prácticamente con toda su pureza, desde el Rif de la vertiente norte más escabroso hasta el pre-Rif de la vertiente sur más llano.

El torno permite utilizar pastas con menos desgrasante y con más plasticidad, permite aligerar las piezas disminuyendo el espesor de las paredes de la vasija y una vez cocidas en hornos de cámara a una temperatura notablemente superior a la conseguida en las horneras a cielo abierto, darán como resultado piezas más ligeras y de mayor calidad, funcionalidad, dureza y durabilidad. Asimismo, estas pastas más plásticas permiten en el torno infinidad de nuevas formas, alargar las piezas, hacerlas más esbeltas y crear labios moldurados de diferentes formas

Al contrario, la cerámica modelada, al no tener la ayuda del giro del torno para montar la pieza, necesita arcillas con más desgrasante y espesores más gruesos para poder subir la pieza, esto unido a la cocción en horneras a cielo abierto que no alcanzan gran temperatura, dan como resultado cerámicas más pesadas, más porosas y que se degradan con más facilidad. En el Rif y en general esta ancestral técnica del modelado que necesita estos tipos de pastas, ha condicionado las formas de las vasijas dando formas simples, poco evolucionadas, no muy altas por lo general globulares, cuellos cortos y labios poco marcados o inexistentes.

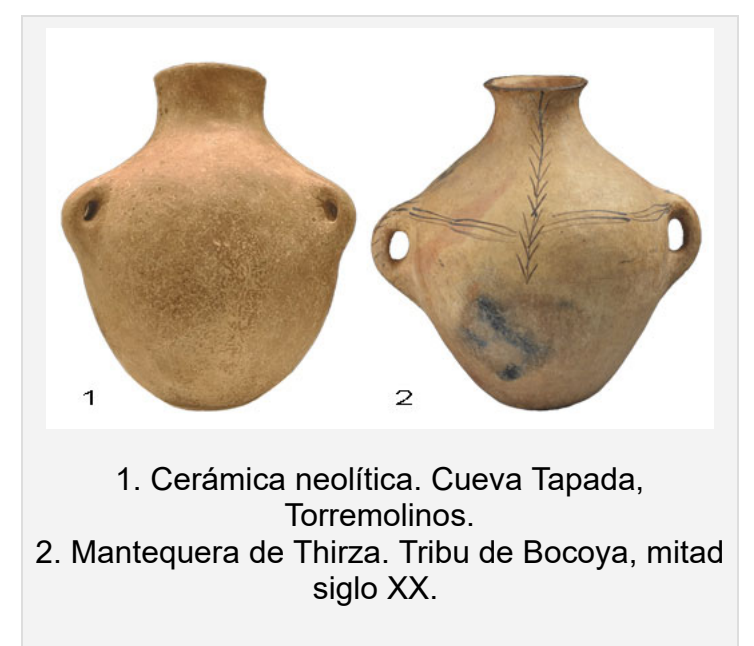


El ser exclusivamente femenino es una de las muestras del arcaísmo de la cerámica rifeña. Desde el neolítico el hombre generalmente dedicaba todo su tiempo a procurar el alimento, la caza, la pesca, la recolección y la agricultura, esto a veces requería largas jornadas lejos del hogar y era la mujer la que quedándose al cuidado del hogar y de los hijos comenzó a modelar la arcilla para fabricar vasijas con las que cubrir sus necesidades. Esto sigue ocurriendo en casi todas sociedades donde su cerámica tradicional es modelada, África subsahariana, América central, Oceanía entre otras, donde las mujeres son alfareras ocasionales y solo hacían las que necesitaban o como mucho algunas más que vendían o cambiaban a modo de trueque en la aldea.

Es a partir de la aparición del torno cuando el hombre aparece relacionado con la cerámica. Esta técnica permite más rapidez en la creación de las vasijas, más cantidad, más solidez para el transporte y es entonces cuando las cerámicas salen ya del ámbito hogar-aldea- tribu y se comercia con ellas y es el hombre el que a partir de ese momento se hace alfarero.

El Rif, hasta el primer tercio del pasado siglo XX, con la ocupación de la vertiente norte por España y la vertiente sur por Francia y con la creación de los dos protectorados, y aunque dependiendo nominalmente del sultán de Fez, se presentaba como un mosaico de pequeñas tribus o cabilas independientes con nula o escasa conexión entre ellas y que solo se coaligaban algunas de ellas cuando había un conflicto o alguna amenaza exterior formando una liga temporal llamada LEF que se disolvía pasado el peligro.

Esta atomización de tribus y el marcado carácter independiente bereber del rifeño se refleja también en su cerámica. Partiendo de una misma técnica de fabricación, modelado y cocción en horneras de suelo, y con mínimas diferencias técnicas entre ellas, cada tribu desarrolla formas diferentes y concretas, así como son diferentes los motivos que componen la decoración de estas que a veces coinciden con sus tatuajes faciales y corporales, y que son su sello de identidad.

La diferenciación de formas entre tribus se aprecia más marcadamente entre las que forman la vertiente sur y las de la vertiente norte, en esta última zona y sobre todo en las de los Beni Boufrah, Bokoya y sobre todo en las de los Ait Ouriaghel sus cerámicas son de forma globular hechas con una arcilla más elaborada y depurada utilizando la chamota como desgrasante y cuidadosamente bruñida, obteniendo como resultado cerámicas con mínimos espesores, teniendo en cuenta el modelado sin torno, y con los mejores acabados de todo el Rif. Estas cerámicas presentan un extraordinario parecido con las de sus vecinas, en proximidad, aunque no en el tiempo, de la otra orilla del mediterráneo, las de la cultura del Argar y sobre todo con las del Bronce Valenciano.
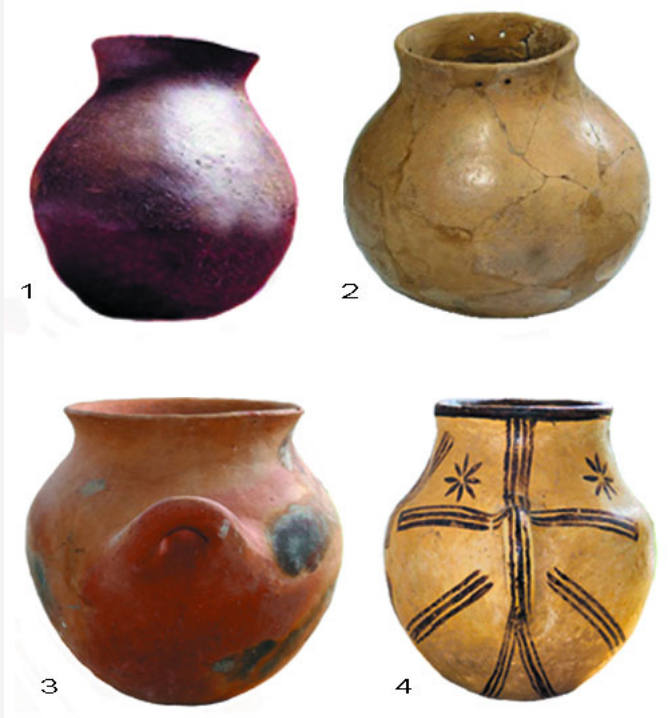

1. Olla Argárica. Antas, 1700-1000 a. C.

2. Loma de Betchi, Paterna. Bronce Valenciano, 1800-1300 a. C.

3. Olla de Thirza. Tribu Bocoya, mitad siglo XX.

4. Olla de Idardouchen. Tribu Aït Ouriaghel, mitad siglo XX. 
Hay constancia de que desde el neolítico temprano ha habido influencias o contacto entre las dos orillas del estrecho de Gibraltar, la cerámica cardial y sobre todo el vaso campaniforme está presente en yacimientos como el de Caf That el Gar, Gar Cahal en Tetuán o Achacar en Tánger, citados anteriormente, todos ellos yacimientos cercanos a la costa del estrecho. Pero, sin entrar en si fue influencia o convergencia cultural, vemos que el arcaísmo de estas cerámicas rifeñas se ha mantenido en esta zona montañosa y aislada del Rif.

\section{Vasijas para lácteos}

La cerámica rifeña es puramente funcional, cada uso define una forma y una decoración concreta y esta vasija no se utilizará para otro uso. En la vertiente norte del macizo los recipientes para los lácteos se usan para contener leche, fabricar mantequilla o lebén, especie de leche cuajada típica de Marruecos, así como para ordeñar. Todas ellas tienen una forma concreta y todas ellas poseen un pico vertedor tubular. Las vasijas que utilizan para ordeñar, llamadas en esta zona takserit, son como las ollitas a la que se le ha aplicado un pico vertedor tubular con un pequeño puente de refuerzo y una pequeña asa en posición vertical en el lado opuesto.

Las vasijas que utilizan para obtener la mantequilla y el lebén, llamadas akchrou o agueruch, son de forma globular idénticas a los cántaros que utilizan para ir por agua a la fuente a las que les han añadido también un pico vertedor tubular en posición perpendicular al plano de las asas. En todas estas vasijas la zona de unión del pico vertedor y las asas es amplia y reforzada dando la sensación de no ser piezas añadidas sino una prolongación del cuerpo de la vasija.

Cerámicas con pico vertedor aparecen ya en el neolítico y en la cultura argárica y aparecen con cierta frecuencia en las sepulturas megalíticas norteafricanas como en el túmulo de Gastel y el monumento megalítico de Sila en Argelia. Gabriel Camps (1962), "Aux origines de la Berbérie - Monuments et rites funéraires protohistoriques", ve los paralelos más próximos en la cerámica calcolítica siciliana y chipriota pero también apunta la posibilidad de un origen neolítico - argárico que del sur de España pasara al norte de Marruecos y de allí a las Islas Canarias donde estos picos tubulares son comunes en la cerámica Guanche prehispánica de origen bereber. Estos contactos entre la cultura argárica y el norte de África parecen más que evidentes dada la aparición en yacimientos pertenecientes a esta cultura de piezas de marfil y huevos de avestruz de claro origen africano.
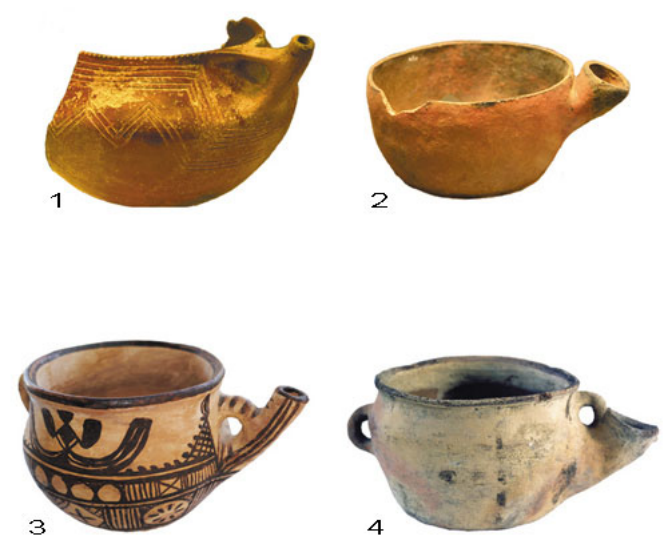

1. Vasija con asa pitorro. Ubrique el Alto, Neolítico.

2. Cultura Guanche. Canarias, Prehispánica.

3. Ordeñadora Idardouchen. Tribu Aït Ouriaghel, mitad siglo XX.

4. Ordeñadora de Douar Farato. Tribu Aït Ouriaghel, mitad siglo XX.

En la vertiente sur del macizo del Rif las vasijas para lácteos son totalmente diferentes; aquí carecen de pico vertedor y las vasijas para ordeñar y recoger la leche son poco significativas y se diferencian poco 
de las formas de sus ollas, pero para la obtención del lebén y la mantequilla han desarrollado una vasija con forma genuina exclusivamente rifeña, particular y original cuyo único paralelo lo tenemos en la cultura calcolítica de los Millares (Almería) y también en esta cultura relacionada con los lácteos. También podríamos relacionarlas en cuanto a forma, aunque no en cuanto a técnica ya que estas están realizadas a torno, con los toneletes de la cultura ibérica. Tanto estas como las rifeñas difieren de las primitivas de los Millares por la adición de pequeñas asas para mejorar su manejo.

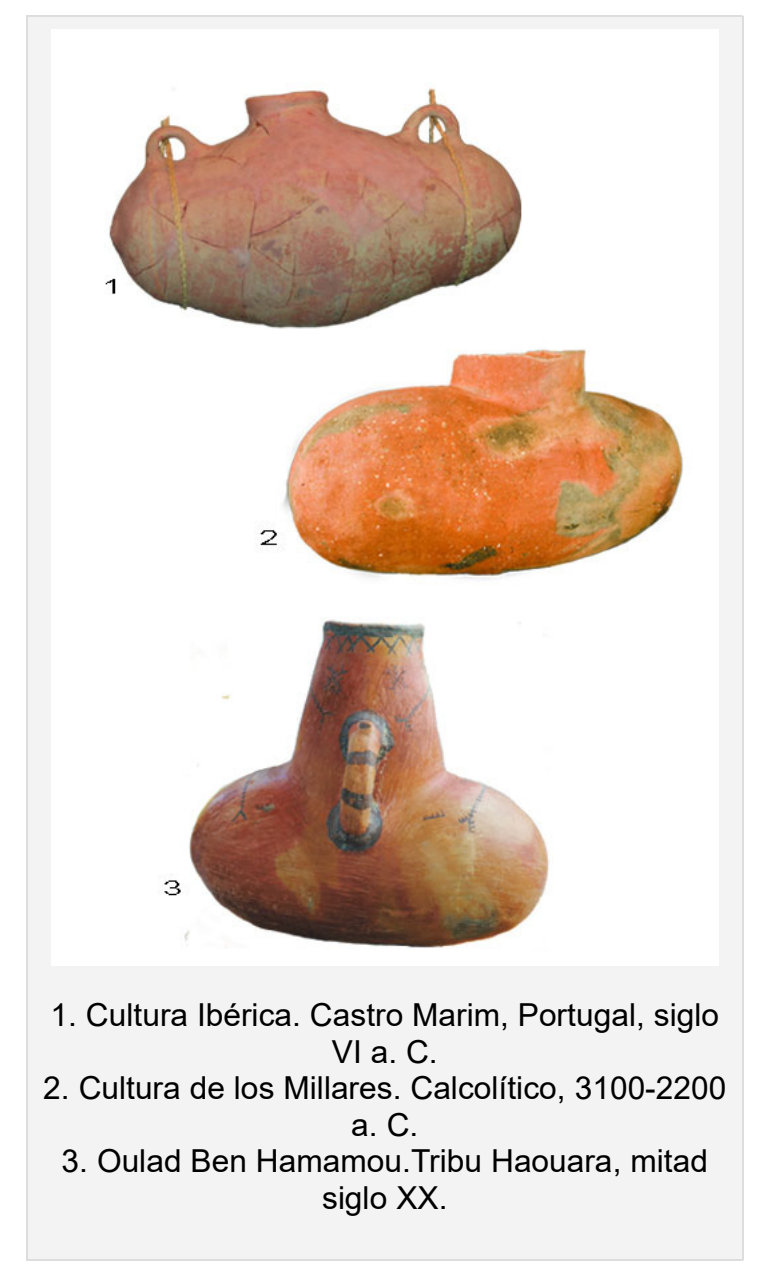

\section{Los vasos geminados}

Otro arcaísmo, en este caso frecuente en ambas vertientes del macizo del Rif y común en bastantes tribus, es la presencia de los vasos geminados. Son otras de las producciones típicas rifeñas. Se pueden presentar en forma diversas, vasos, pequeños platos, cántaros, pequeños botijos, etc. unidos por el cuerpo y generalmente con un asa puente entre los dos recipientes y que las alfareras siguen fabricando con técnicas y formas similares a las primitivas cerámicas del neolítico y del bronce mediterráneo.

Aunque actualmente casi en desuso estos vasos geminados se usan o se usaban en celebraciones. Encontramos varias formas de cerámica geminada como los pequeños platos llamados, tabsil machruk, los de forma globular y con dos vertedores en forma de pezón, llamados biberones, los de forma de botella de cuello alargado parecen haber tenido un uso ceremonial o ritual, como los cántaros geminados de la tribu de los Beni Mesguilda llamados Abukal larossa, que significa cántaros de los novios o cántaros de boda. 


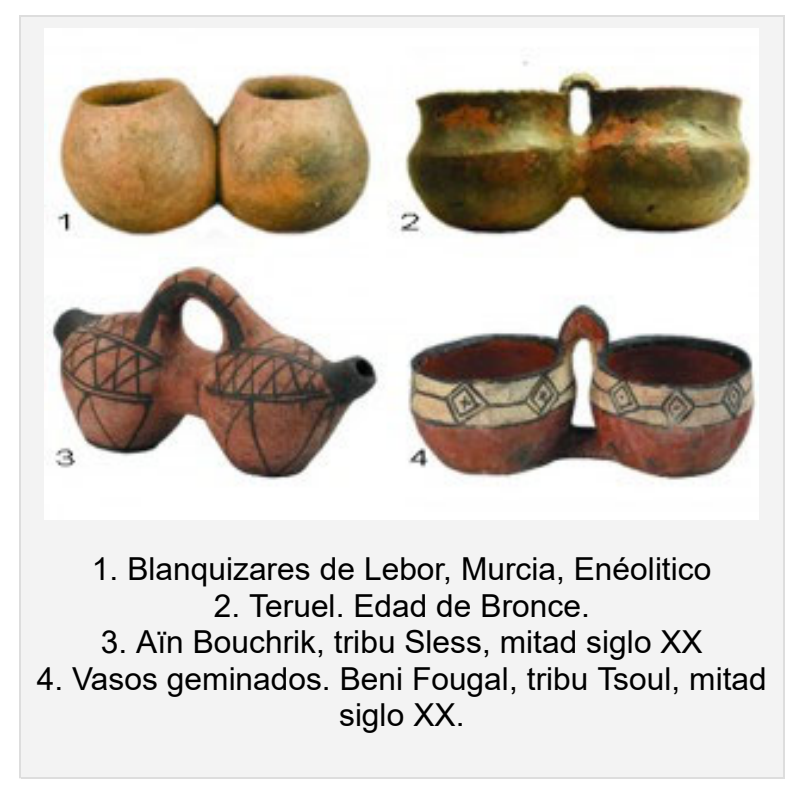

Los vasos geminados rifeños parecen tener un origen peninsular ya que aparecen con cierta frecuencia en yacimientos que van del neolítico, calcolítico, bronce, llegando hasta la cultura ibérica y al contrario están totalmente ausentes en la cultura megalítica norteafricana.

\section{Las miniaturas y los vasos zoomorfos}

La realización de miniaturas en cerámica de objetos diversos, pequeños anafes utilizados como quemadores de incienso en cualquier ceremonia, cantaritos, ollitas, etc. son corrientes en algunas tribus rifeñas. La mayor parte de estos son tenidos en la actualidad como simples juguetes, pero estas miniaturas poseían en la antigüedad una gran carga esotérica, tal como lo podemos apreciar aún en la actualidad en la tribu de los Aït Ouriaghel donde sus alfareras realizan unas babuchas de barro en miniatura, las cuales cuelgan en la pared de sus casas, como amuletos portadores de buena suerte ya que la leyenda dice que, si por algún maleficio entra en la casa la mala suerte, estas babuchas la alejarán. También las tortugas formaban parte de un rito protector hacia el recién nacido. Este rito consistía en sacrificar una tortuga, deshuesarla y suspender sus huesos por encima de la cuna y con su carne una vez seca se trituraba y se esparcía alrededor de la cuna. "Makilam, Signes et rituels magiques de femmes Kabiles", seguramente, tenía como fin alejar la muerte del recién nacido ya que la mortandad infantil y la de recién nacidos era altísima. Por la dificultad de encontrar tortugas vivas estas serían reemplazadas por tortugas de barro siguiendo así este ritual de protección al recién nacido y a la infancia.

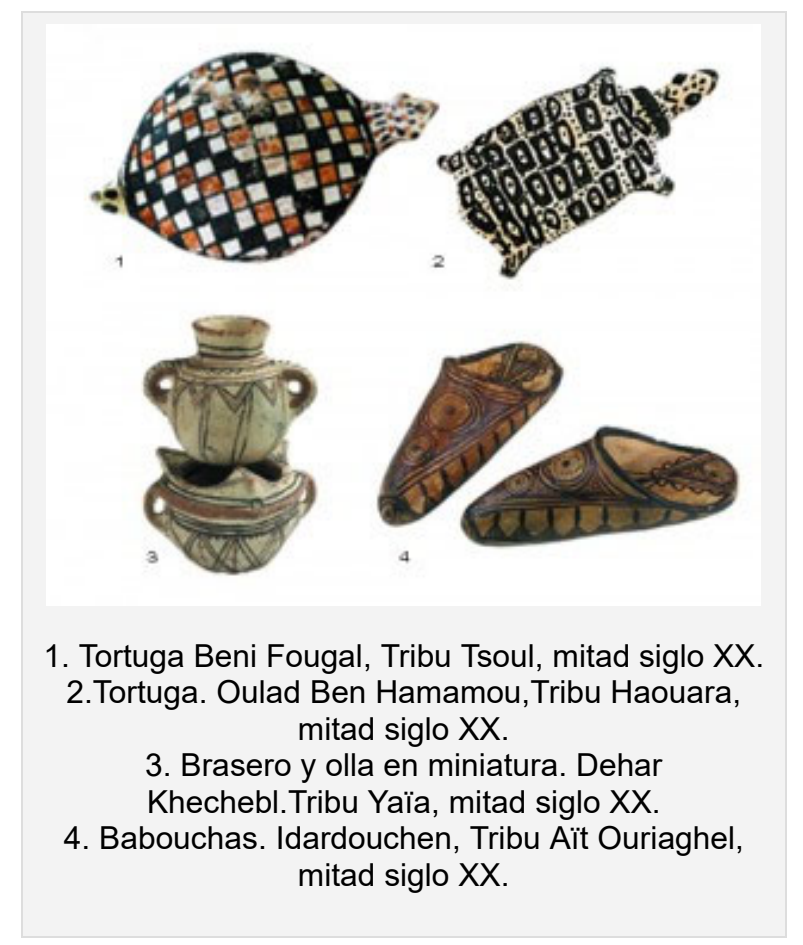


La serpiente de barro era otra representación animal muy utilizada en el día a día. Esta se depositaba cerca de los puntos de agua, cerca de la puerta de entrada a la casa y alrededor de las cunas para alejar las alimañas. En la tribu de los Oulad Ben Hamamou las alfareras para proteger el agua de uso humano, aplican unas serpientes en relieve o dibujada cerca de la boca de las tinajas de agua para evitar que los animales se acerquen a beber.

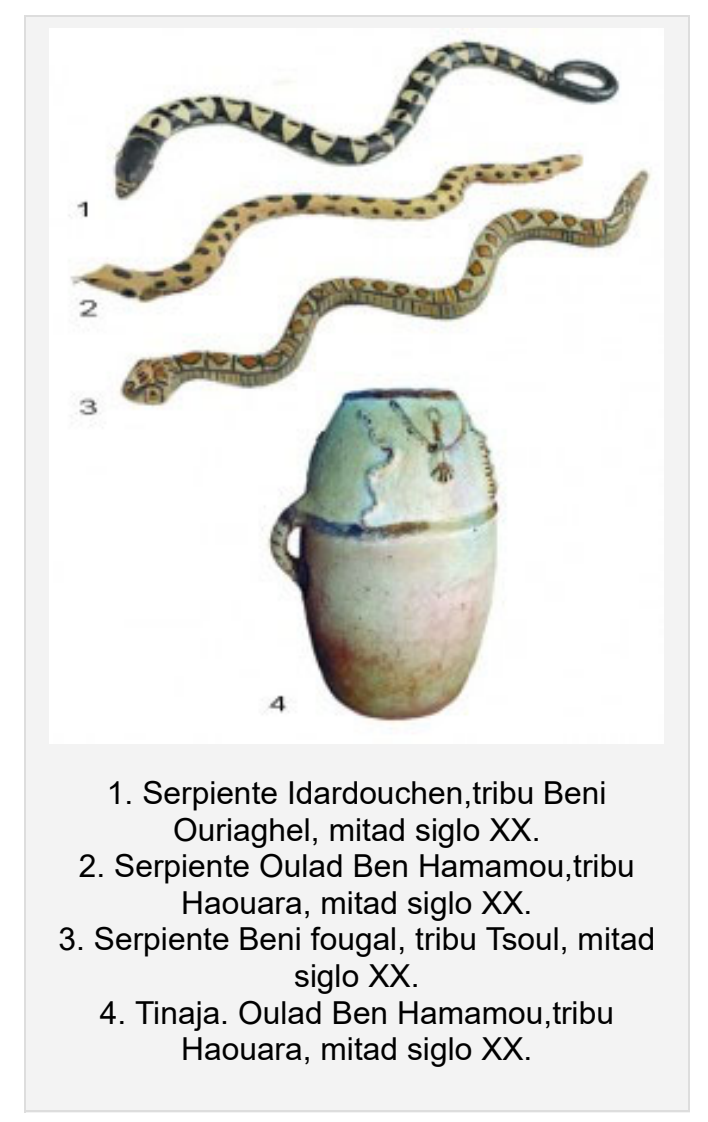

También, con un origen ritual o votivo perdido, y tenidos actualmente como simples juguetes, las alfareras rifeñas representan en barro su fauna más próxima, burros, pollitos etc. Las miniaturas de las vasijas de uso común, las encontramos también formando parte del ajuar funerario en las necrópolis bereberes en túmulos y megalíticas del Magreb, así como también posteriormente en diversas culturas antiguas del oriente mediterráneo. Actualmente, guardando toda su estética, pero desprovistas ya de su carga simbólica, las vemos convertidas en simples objetos decorativos. Mención aparte merecen los vasos zoomorfos que realizan las alfareras de la tribu Haouara dentro de una tradición que poco o nada ha variado desde los vasos rituales de los enterramientos en la cultura megalítica del III milenio a. C. del sur de la península ibérica.

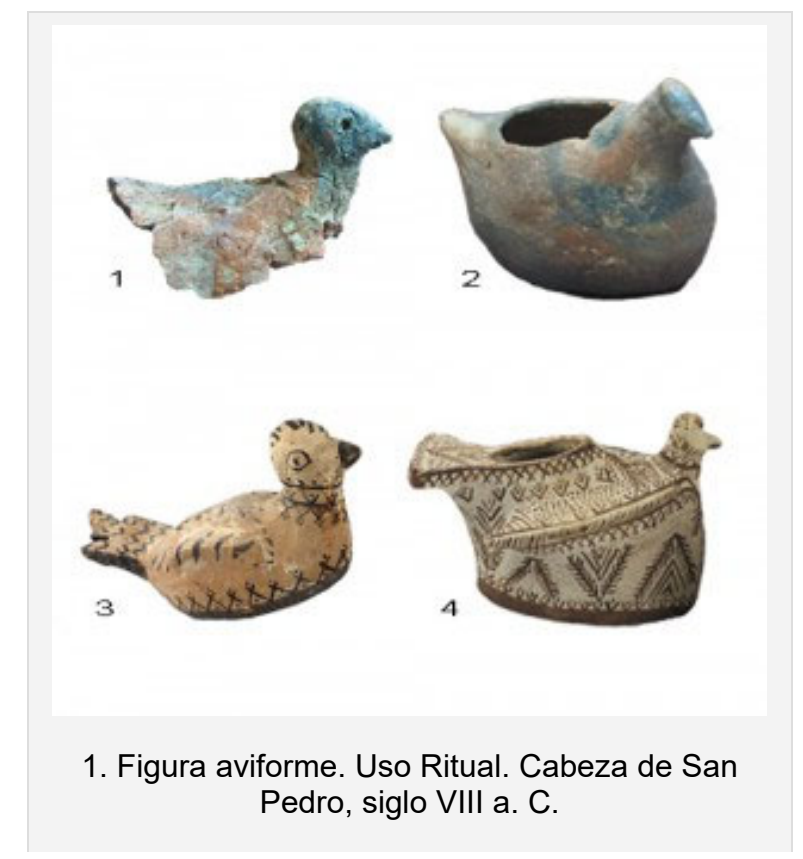


2. Vaso ritual. La Zarcita, Santa Barbara de Casas, siglo IV-III a. C.

3. Figura aviforme. Oulad Ben Hamamou, tribu Haouara, mitad siglo XX.

4. Vaso ritual. Oulad Ben Hamamou, tribu Haouara, mitad siglo $X X$.

\section{Símbolos cruciformes}

Aunque el cristianismo llegó al Magreb durante la romanización y estuvo presente hasta la llegada del Islam, no parece que las cruces, tan frecuentemente representadas en las cerámicas rifeñas, por lo menos en parte, sea una herencia de esta fe, ya que signos cruciformes que aparecen en algunas vasijas rifeñas son bastante más antiguos e idénticos a los que aparecen en grabados rupestres relacionados con algunas necrópolis de túmulos y megalíticas norteafricanas todas ellas anteriores al cristianismo.

El signo de la cruz aparece, bajo diferentes formas desde la más remota antigüedad y ha formado parte de la simbología de prácticamente todas las culturas. Los signos cruciformes son frecuentes en las cerámicas de casi todo el Rif. Aparecen como cruces griegas, cruces de San Andrés, potenzadas y cruces de Malta. Generalmente se representan aisladas repartidas por el cuerpo de la vasija, o bien, representadas en el interior de figuras geométricas, triángulos, rombos, círculos, etc. A veces estas cruces forman motivos más complejos al rellenar sus ángulos internos con una serie de chevrones o bien las aspas de la cruz se modifican como intentando representar figuras antropomorfas. En algunas tribus, superponiendo dos cruces, forman figuras en forma de estrella, ocupando los mismos espacios en las vasijas y con su misma carga simbólica.

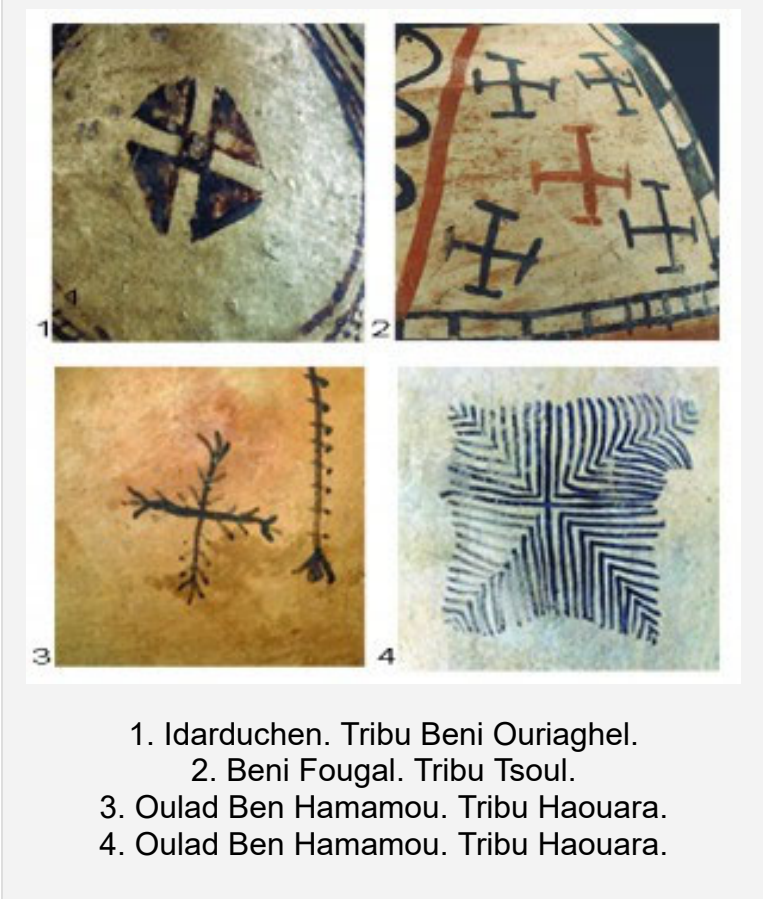

Las cruces aparecen también representadas en el mundo bereber sobre sus tapices y sobre todo y en multitud de formas diferentes en los tatuajes tanto corporales como faciales de las mujeres, tan característicos del mundo rural bereber. Dentro de los símbolos cruciformes aparece uno, que por su abundancia en la cerámica rifeña y presentarse bajo diferentes formas, trataremos aparte. Se presenta este símbolo como una cruz de San Andrés en la que los extremos de cada brazo tienen una prolongación acodada en ángulo agudo y con los extremos encontrados. 

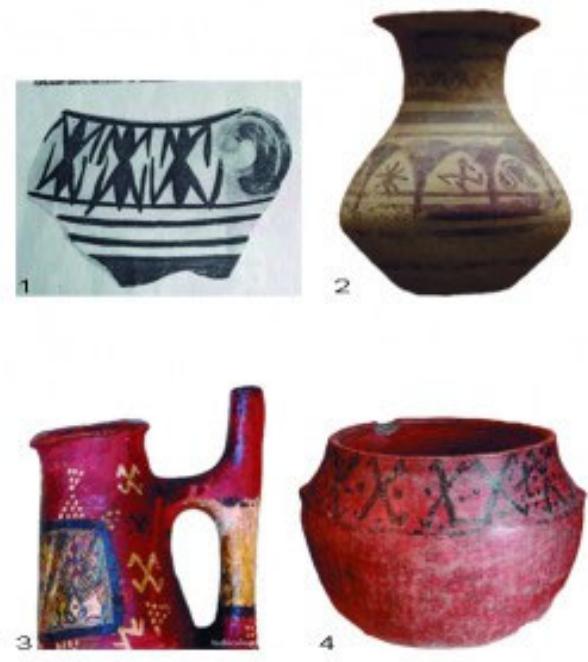

1. Yacimiento arqueológico de Banassa, Marruecos. Época púnica.

2. Vasija Iberica, siglo III-I a. C.

3. Vasija Maatkas, Gran Kabilia, $1^{a}$ mitad siglo XX (fotografía de María Sáez).

4. Sagel tunecino, $1^{a}$ mitad siglo $X X$.
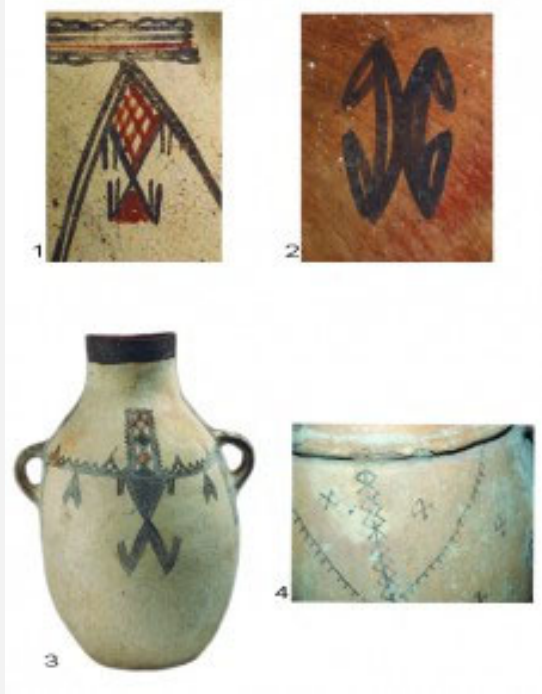

1. Beni Mestara.

2. Beni Boukmat.

3. Taounate Louta.

4. Oulad Ben Hamamou.

En el Rif se puede encontrar este signo aislado, como ocurre en algunas cerámicas de Oulad Ben Hamamou, pero es más corriente encontrarlo formando parte de otros motivos más complejos. Aparte del Rif este símbolo aparece con cierta frecuencia en algunas cerámicas modeladas del Sahel tunecino y sobre todo en las de la tribu de los Maatkas en la Gran Kabilia argelina, todas ellas comparten con las rifeñas un origen común tanto en su técnica de fabricación como en su marcado origen bereber.

Carlos Borras en su tesis doctoral sobre la cerámica rifeña incluye este signo en el grupo que él denomina "raniformes" con un significado equivalente a la simbología de la rana. Por su parte J. B. Moreau (1951), en su trabajo sobre la simbología de la cerámica modelada femenina argelina, relaciona este símbolo con la swastika como también lo relaciona con la araña. Este signo, con múltiples variaciones de formas, aparece también en la fase final de la cultura ibérica (siglos III al I a. C). Los 
investigadores que se han interesado por estas cerámicas, como A. Garcia Bellido (1954), C. Aranegui (1987), M. A. Elvira (1979) y sobre todo P. Moret (1989) que dedica una monografía a este signo, lo denominan, sin ponerse de acuerdo en atribuirle un sentido o significado concreto, como araña de agua o "zapatero "por su semejanza con este insecto acuático (Guerris Lacustris, Linné).

En cuanto a su origen P. Moret, en su trabajo sobre las cerámicas ibéricas, ya apunta a atribuirle un posible origen púnico, apoyándose en las observaciones que $\mathrm{M}$. Astruch y $\mathrm{M}$. A. Elvira hacen sobre un cierto parecido con el símbolo que aparece pintado sobre cáscaras de huevos de avestruz encontradas en la necrópolis púnica de Villaricos (Almería) datada entre el siglo VI y V a. C.

También coincidiendo con esta datación pero esta vez más cerca del Rif, en el norte de Marruecos en las excavaciones arqueológicas realizadas en el sitio prerromano de Banasa, en la orilla del rio Sebou, realizadas por $A$. Luquet, aparecen a más de 10 metros por debajo del suelo moderno y a más de siete metros del suelo romano abundantes trozos, algunos de ellos fallados de cocción lo que evidencia la proximidad de un horno, con decoración reticulada muy parecida también a la de la cerámica actual rifeña, pero lo que más llama la atención al excavador es la presencia de un nuevo signo similar al que nos interesa y similar al de la forma ibérica B1, presente en Archena, La Alcudia y Liria. Luquet asegura que todas estas piezas pintadas pertenecen sin duda a una producción local por los hornos hallados, pero asociada a una tradición púnica por la tipología de las cerámicas y la presencia en ellas de algunos grafitis con caracteres púnicos.

Esto nos hace pensar que esta decoración sea de un origen autóctono bereber pasada al mundo púnico y posteriormente al mundo ibérico a través de la influencia que ejerció Cartago en gran parte de la zona que ocupó la cultura ibérica, hasta la romanización.

Parece que la dilatada pervivencia de estos signos a través de los siglos hasta nuestros días, se debe a su localización sobre cerámicas de una clara tradición bereber que se ha mantenido a través de los siglos aislada sin que hubiera sido influenciada por el exterior ni en su arcaica técnica de realización, modelado a mano sin torno y cocción sin hornos, simplemente en horneras, como en su decoración, encerrados en los agrestes sistemas montañosos que bordean la costa mediterránea del Magreb donde secularmente se ha defendido la identidad bereber.

\section{Símbolos antropomorfos}

El Rif fue tempranamente islamizado y aunque el Corán no permite la representación humana, por el aislamiento secular y su marcado carácter bereber, sus alfareras la han seguido representando de una forma más o menos esquematizada.

En casi todas las culturas se manifiestan representaciones de divinidades femeninas protectoras de la agricultura y la fecundidad atribuidas a la Gran Madre y son frecuentes desde el neolítico. Ya en la cultura micénica vemos figuras femeninas, posiblemente representaciones de alguna diosa, con los brazos alzados en posición orante. En la tribu de los Ait Uriaghel, las alfareras de la zona comprendida entre los ríos Nekor y Ghis, representan, en alguna de sus vasijas, una forma humana esquematizada con los brazos extendidos en posición orante.

Quizás el paralelo más claro de esta representación, coincidiendo con Carlos Borras, pero modificado por la esquematización geométrica típica de la cultura bereber, lo podemos apreciar en el llamado Bronce Carriazo del siglo VII o VI a. C. y atribuido a la cultura tartésica. Maluquer de Motes ve en este bronce la representación de la diosa egipcia Hator que con el tiempo se identifica con la diosa Isis, con funciones análogas a la Ischtar mesopotámica y a la Astarté fenicia y a la Tanit cartaginesa. Posiblemente fueran estos últimos los que importaron esta deidad al occidente mediterráneo representada por los metalúrgicos tartesios y esquematizada por las alfareras beréberes en sus vasijas.

Por otra parte F. de Santos Moro (1991) y J. A. Ramón Burillo (1987) creen ver a una figura antropomorfa sobre la representación esquemática de la denominada barca solar, en relación con la mandyet, la barca sobre la que el dios solar egipcio Ra hacia su viaje durante el recorrido diario del sol.

En gran parte del Maghreb, la escenificación del momento de presentación de la recién casada cuando es expuesta a los invitados es denominada como jelwa, esta manifestación, aunque esquematizada, la 
podemos apreciar en los tapices bereberes, así como también frecuentemente en algunos tatuajes tunecinos. Está también denominada como jelwa la actitud en que es representada la diosa por excelencia del mundo púnico-bereber, venerada desde Egipto hasta el occidente magrebí, Tanit. Algunos quieren ver el origen de esta divinidad en la diosa egipcia Neit, que tras el contacto entre el mundo púnico y el líbico-bereber adoptará el articulo femenino Ta - Neit convirtiéndose en Tanit. Ella era la diosa de las cosechas, de la abundancia, de la fecundidad, de la fertilidad y en algunas inscripciones se la denomina "madre" y en ocasiones se la representa con los brazos en alto en posición orante o de protección.

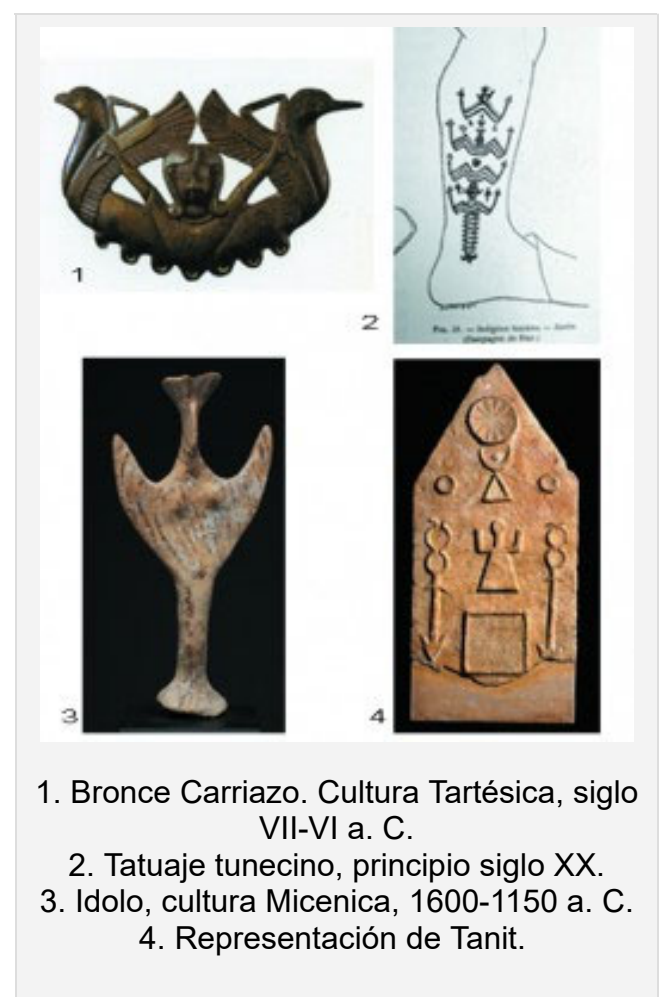

En el Rif, por las características de su costa agreste y escarpada, la bahía de Alhucemas y en ella la costa de los Ait Ouriaghel es la única que se presta a un refugio portuario más o menos seguro a contactos con el interior del país, donde chipriotas, cretenses, fenicios y cartagineses pudieran instalar sus factorías. Por otro lado, la misma zona cerrada por el macizo del Rif y el carácter hermético e independiente de sus pobladores ha permitido mantener a través del tiempo en sus cerámicas su característica decoración geométrica y en su iconografía algunos motivos, aunque esquematizados, de sus divinidades.

En unas vasijas, destinadas a guardar la leche, de la misma tribu, también podemos apreciar unas figuras antropomorfas más o menos esquematizadas. Estas están representadas en las asas tomando estas como cuerpo y desarrollando a continuación cabeza y extremidades.

En la vertiente sur del Rif, el Pre-Rif, en el aduar Oulad ben Hamamou perteneciente a la tribu Haouara las alfareras representan en algunas de sus orzas, jebbana, en relieve, figuras humanas esquematizadas, pero con cierto realismo en posición orante. También en sus mantequeras, afquir, aparecen figuras humanas sumamente esquematizadas que nos hacen recordar algunos tatuajes de Túnez. A este propósito, Bertholon (2011) quiere ver en estas representaciones un claro origen púnicocartaginés y en concreto relacionado con la diosa Tanit. 


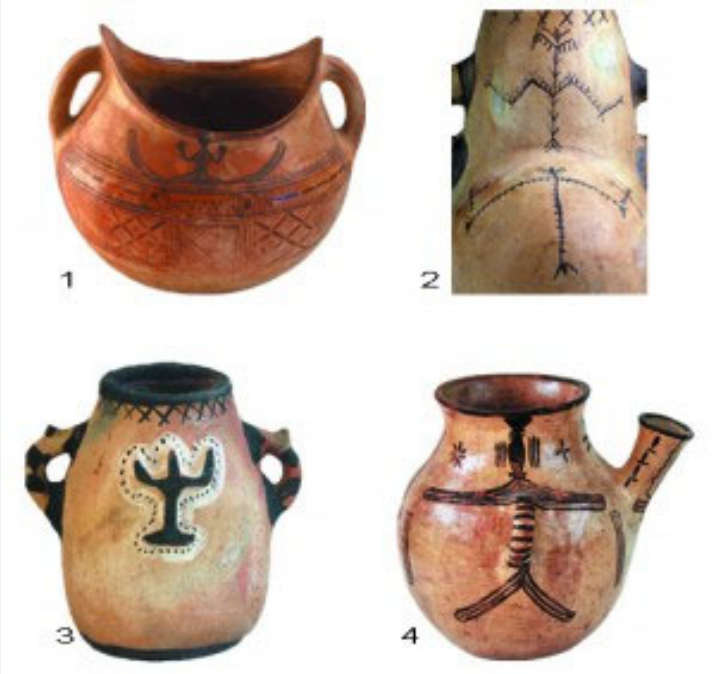

1. Vaso de pico de pájaro. Idarduchen, tribu Beni Ouriaghel, mitad siglo XX.

2. Mantequera. Oulad Ben Hamamou, tribu Haouara, mitad siglo XX.

3. Orza. Oulad Ben Hamamou, tribu Haouara, mitad siglo $X X$.

4. Lechera con asa pitorro. Idarduchen, tribu Beni Ouriaghel, mitad siglo XX.

Fuera de estas tribus las representaciones humanas son escasas, pero a veces se pueden apreciar motivos antropomorfos extremadamente esquematizados y de difícil interpretación.

\section{Otros símbolos}

\subsection{La mano}

En la cultura bereber la mano tiene un gran poder de protección y de alejar los maleficios. Todos los años cuando llega la primavera, las casas del medio rural y sobre todo las de adobe, necesitan ser reparadas. Este trabajo de mantenimiento tanto del exterior como el del interior de las casas es realizado por las mujeres, por este motivo volvemos a encontrar tanto en la fachada como en las paredes o techos de las habitaciones, manos abiertas protectoras, del hogar y de la familia.

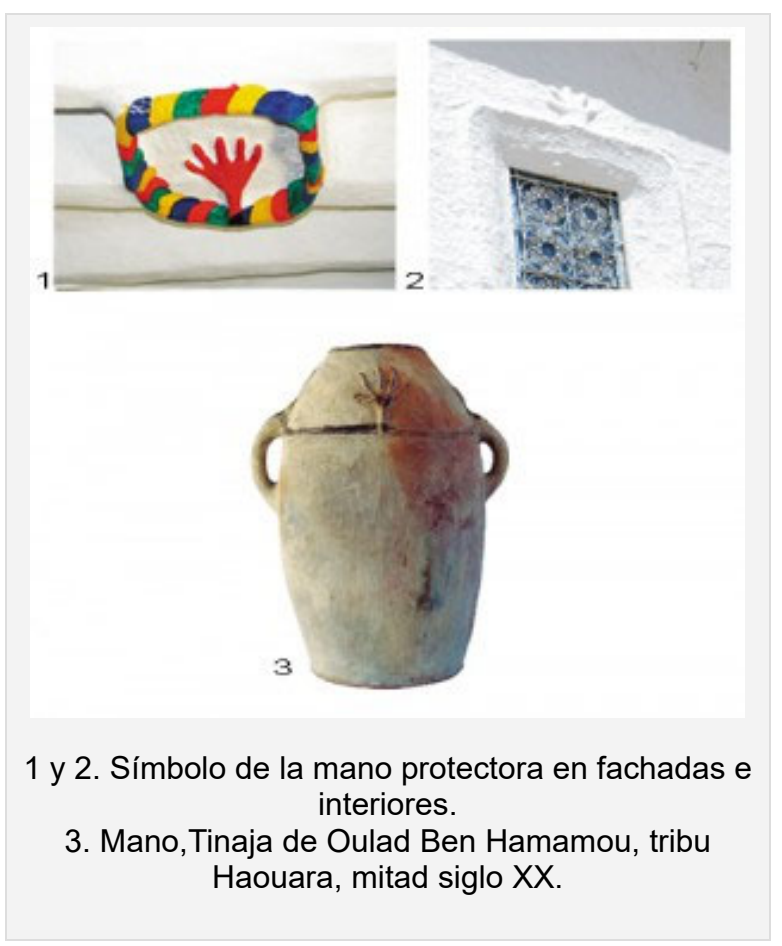


En el Rif, en la tribu de los Bokoya, hay un lugar santo de origen preislámico llamado Lala Mereka. Una gran roca, un viejo acebuche y una habitación construida sobre un hilo de agua de una fuente cercana forman el santuario. A este lugar santo, de uso exclusivo femenino acuden las mujeres a realizar sus ritos y plegarias y a invocar salud para ellas y sobre todo para sus hijos, paz en el matrimonio, y fecundidad, así como protección contra todos los males y de los buenos deseos físicos y místicos relacionados estrechamente con el mundo de las mujeres. Después de los rituales de rigor las mujeres se embadurnan la palma de las manos con barro mojado como símbolo de la buena suerte, la baraka, y dejan su impronta en las paredes interiores de la habitación con el fin de que el deseo se cumpla, y la vemos representada, aparte de en las cerámicas, pintada en algún lugar de las casas o en sus fachadas, disimuladas entre el grabado de sus joyas o en sus tejidos.

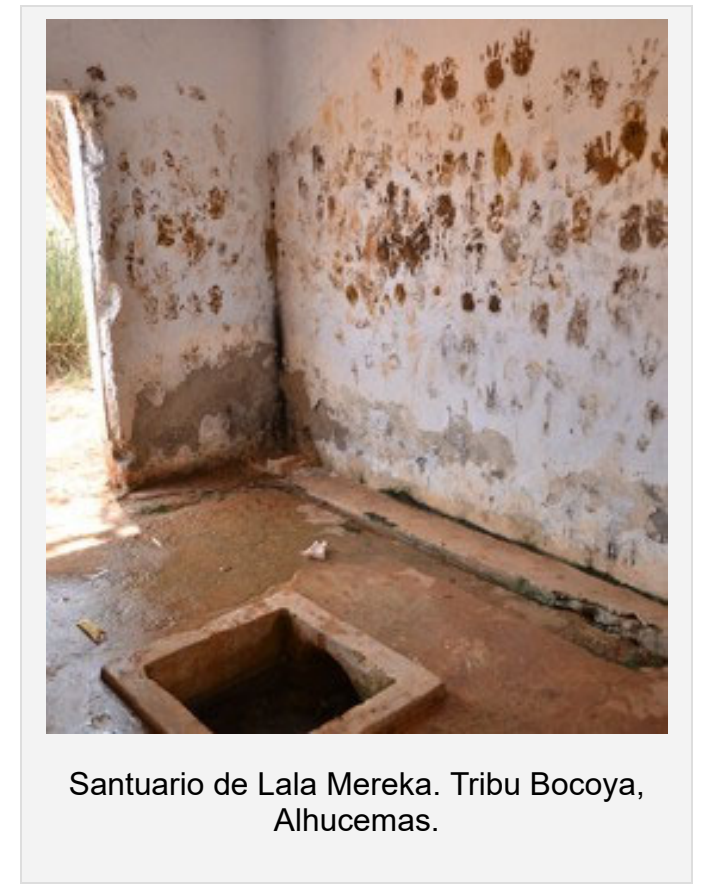

Igualmente la podemos ya observar con indudable carga simbólica en las manifestaciones de numerosas culturas en todos los continentes desde la cueva de las manos perteneciente a la cultura de los indios Tehuelches en Argentina, a ser un motivo pictórico recurrente en el arte paleolítico del sur de Francia y norte de España, pero parece ser que la representación más antigua la da una silueta de mano pintada en la cueva de Leang Bulu en la isla de Sulawesi en las Celebes, datada por los arqueólogos de la universidad de Criffith de Australia sobre unos 40.000 años de antigüedad y parece ser que esta mano se puede considerar como la primera manifestación artística o religiosa del ser humano.

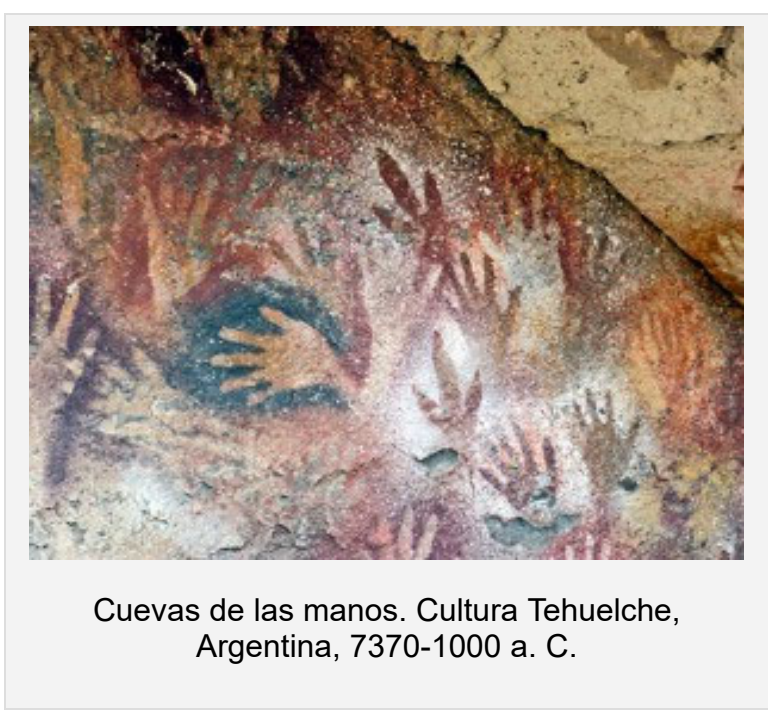

También son las manos la representación del jeroglífico de Ka que representa el alma y la inmortalidad en la iconografía del antiguo Egipto. Pero quizás la representación preislámica de las manos más próxima a la mano de Fátima, posiblemente heredada de este jeroglífico, la vemos en algunas de las estelas votivas dedicadas a la diosa Tanit del siglo III a. C. de Cartago y es posible que este símbolo 
pasara, por sincretismo, de la cultura púnica al mundo bereber circundante posteriormente islamizado.
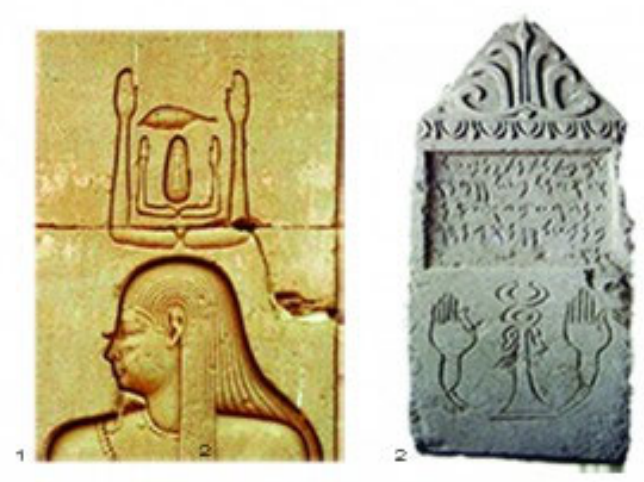

1. Símbolo egipcio Ka.

2. Estela votiva. Púnica, Cartago.

El símbolo Khamsa, número cinco en árabe, muy integrado y admitido en el islam, referido a los cinco dedos de la mano y más comúnmente llamado mano de Fátima, en honor a la hija del Profeta, es un signo muy extendido por todo el Magreb como amuleto protector contra el mal de ojo. Su representación con los cuatros dedos juntos y el pulgar separado pretende frenar o parar cualquier maleficio a la persona que lo porte.

\subsection{Los ojos}

Desde la más remota antigüedad las representaciones de ojos se manifiestan con una cierta relación simbólico-ritual. Así los vemos ya en el IV-III milenio a. C. en los ídolos placa oculados, en los enterramientos de la cultura megalítica del suroeste de la península ibérica.

Pero quizás la representación, si no la más antigua, pero sí la más conocida, del ojo como símbolo sea el Udyat u ojo de Ra o de Horus, símbolo de protección y gracia divina en la antigua civilización egipcia.

Los ojos los vemos representados sobre cerámicas en la cultura de los Millares. Esta cultura perteneciente a la edad del cobre se desarrolla en el sureste de la península ibérica entre 3.200 al 2.200 a. C. Posteriormente y sobre cerámicas parecidas vemos representados ojos ya en plena época de la cultura ibérica 500-400 a. C.

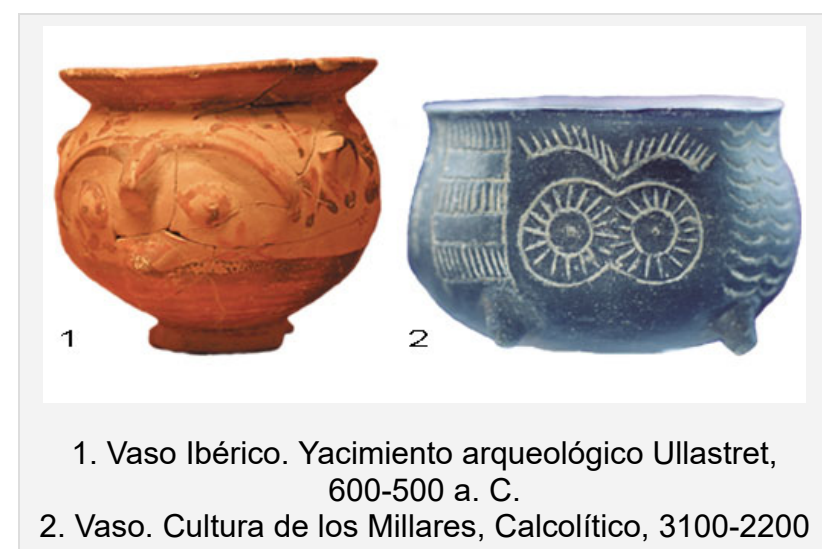
a.C. 


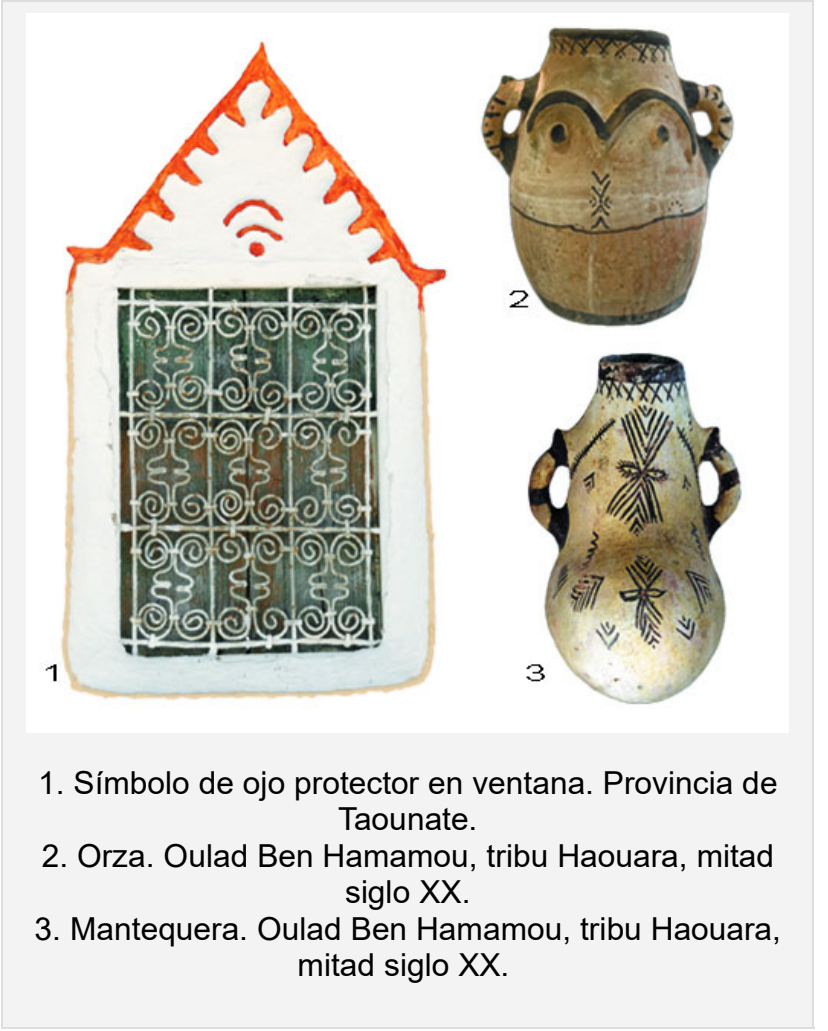

En el Magreb el ojo se representa solo o a veces junto al amuleto de la mano de Fátima. En el Rif lo podemos ver a veces pintado, tanto en el interior como en el exterior de las casas, como símbolo de protección.

En el aduar Oulad Ben Hamamou de la tribu Haouara, situado en la zona cerealista del Pre-Rif, sus alfareras los representan sobre sus vasijas, a veces aislados y de una forma realista y otras veces de forma más esquematizadas asociados a chevrones representando haces de trigo, con un claro contenido simbólico destinado a invocar protección para sus cosechas.

En esta tribu las representaciones de los ojos sobre las cerámicas las podemos ver a veces y otras veces en una de las escasas y menos corrientes formas de decoración en esta zona del Rif, en relieve, y con una marcada expresividad y realismo.

A veces vemos este símbolo pintado sobre alguna puerta o ventana como signo de protección o para alejar los malos espíritus y también labrados y disimulados en sus joyas con el mismo fin.

\subsection{Los triángulos}

La asociación del triángulo a un cierto uso ritual lo vemos ya en el IV-III milenio a. C. en los abundantes ídolos placa aparecidos en los enterramientos de la cultura megalítica del suroeste de la península ibérica.

El triángulo es también un pictograma de la diosa púnica Tanit, como lo podemos apreciar en las estelas votivas dedicadas a esta diosa y en las terracotas que la representan, utilizadas como talismán curativo, mágico y religioso.

En la necrópolis del yacimiento neopúnico de Tiddis, del segundo siglo antes de nuestra era, situado en la región de Constantina (Argelia), aparecen en tumbas bereberes, unos vasos decorados con una serie de triángulos que son semejantes a los que han dibujado las alfareras beréberes hasta final del pasado siglo en la Kabilia y es uno de los motivos decorativos más recurrentes que podemos encontrar en las cerámicas rifeñas.

No deja de sorprender el parecido de las series de triángulos de algunas vasijas rifeñas con las de la cueva prehispánica, de indudable origen bereber, de Galdar (Gran Canaria), la datación de esta cueva es del siglo VII al XV d. C. Lo mismo sucede con las paredes decoradas de algunas casas bereberes del siglo XI. Actualmente todavía podemos observar series de triángulos en las decoraciones que las mujeres rifeñas realizan, en verano después de pasadas las lluvias, en sus casas. 


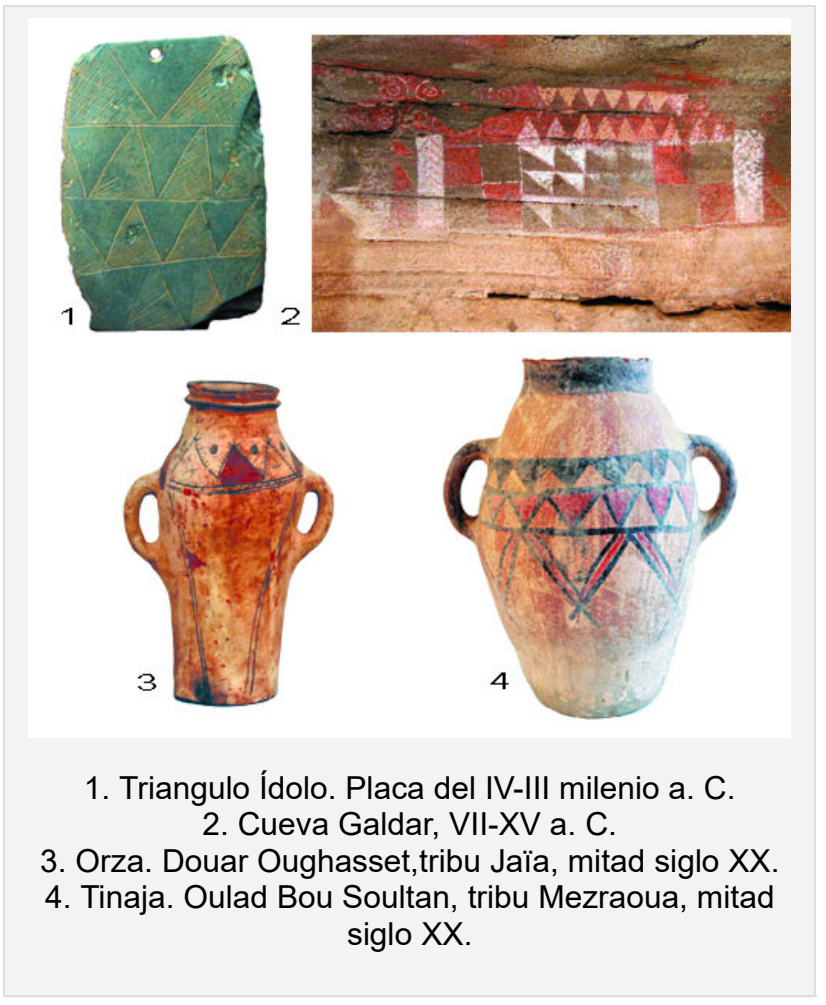

Las alfareras rifeñas, en su lenguaje decorativo, tienden a la esquematización geométrica, sobre todo triangular, de todo ser vivo y lo representan ya sea vacío, reticulado, en damero o relleno de chevrones. El triángulo es una de las formas geométricas más representadas. Siguiendo a Gabriel Camps (1961: 380): "Ce décor correspond à un sentiment profond, a une véritable conception esthetique indissociable du milieu rural berebere".

Si el triángulo está representado con el vértice hacia arriba está considerado un símbolo masculino y si lo está hacia abajo una identificación simbólica femenina relacionada con la fertilidad.

\subsection{Las serpientes}

El culto a las serpientes se ha podido constatar desde los tiempos prehistóricos. Su renovación periódica con el cambio de su piel y su cíclica hibernación y posterior despertar las han potenciado como símbolo de la inmortalidad.

En el antiguo Egipto aparecen formando parte del tocado de Ra y la cobra representada sobre la cabeza es adoptada para representar a los faraones, llegando a identificarse con los mismos dioses.

Sobre cerámica, se encuentran ya representadas las serpientes en el vaso de Khafage perteneciente al dinástico arcaico sumerio hace 2.600 años a. C. Posteriormente las vemos también en Chipre, en casi todas las culturas antiguas de cuenca mediterránea y en la península ibérica sobre vasijas de las culturas tartesia e ibérica.

En la antigua Grecia, aparece su culto con la diosa de las serpientes del minoico medio relacionada con la fertilidad. Posteriormente la vemos curando enroscada al báculo de Esculapio. En el Génesis es el símbolo protector y custodio del árbol de la vida y posteriormente en el nuevo testamento, con el cristianismo, se la identifica con el diablo tentador enemigo de los hombres. Moisés fabrica una serpiente de bronce cuya sola visión curaba a los israelitas mordidos por ellas y que Yahvé les había enviado por sus pecados.

Con esa misma intención, curativa o profiláctica, desde tiempo inmemorial, las alfareras beréberes representan en barro serpientes que después colgaban de vigas o colocaban en algún rincón de sus casas cerca de sus puertas o ventanas para proteger los alimentos y evitar así la entrada de animales indeseados en la vivienda. 

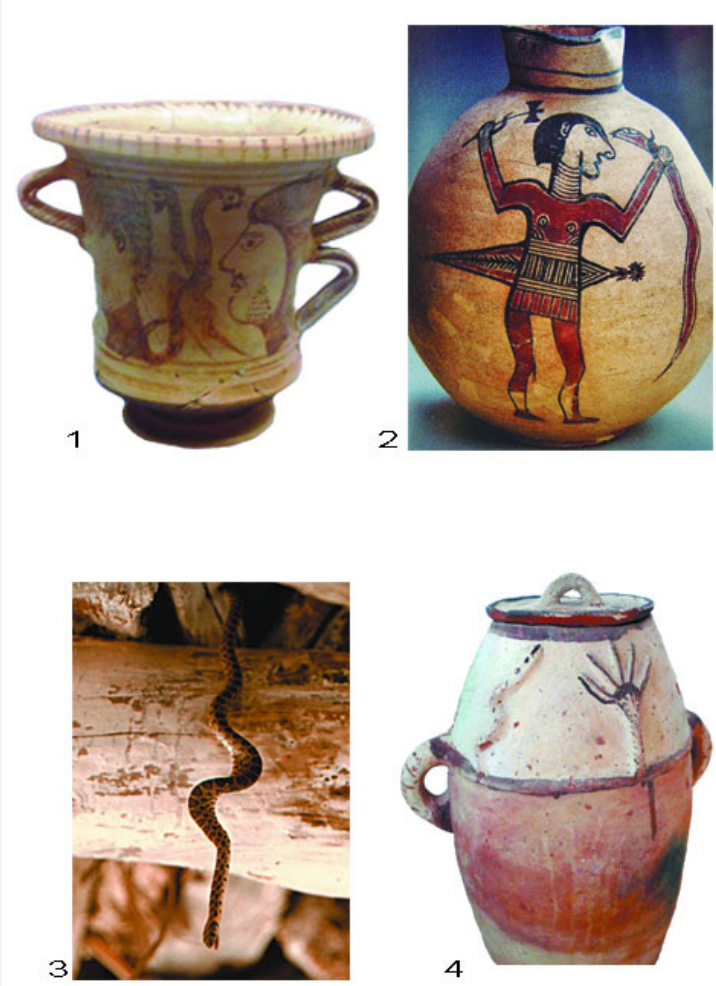

1. Vaso de la Alcudia. Cultura Ibérica, Elche.

2. Vasija. Chipre, hacia 650 a. C.

3. Serpiente natural, tribu Bocoya.

4. Tinaja. Oulad Ben Hamamou, tribu Haouara, mitad siglo XX.

También las vemos modeladas en relieve sobre sus jabias (tinajas), mechmar (braseros), etc. o representadas pintadas de forma más o menos esquemática sobre sus vasijas.

\section{La decoración con pigmentos vegetales (resina de lentisco)}

La presencia de huevos de avestruz decorados es común en los enterramientos relacionados con yacimientos arqueológicos fenicio-púnicos. Los motivos de esta decoración son variados abundando los motivos florales y suele estar realizada con pigmento mineral en ocre rojo, pero en la necrópolis de Villaricos, la antigua Baria fenicia, en la provincia de Almería aparecieron una serie de cascarones de huevos de avestruz, sobre todo en los tipos 1a, 1b, y 1c de la clasificación que hizo Miriam Astruch (1951), en los que los motivos de su decoración y sobre todo la técnica y el pigmento usado las diferenciaba de la gran mayoría y en las que la similitud con las cerámicas contemporáneas de la tribu de los Ait Ouriaghel no deja de ser sorprendente y evidente en algunos de sus aspectos: La decoración ocupa prácticamente la totalidad del vaso. Esta decoración se desarrolla alrededor del vaso a modo de metopas. Los motivos de la decoración suelen ser repetitivos pero combinados de forma que resulta de gran rareza encontrar dos vasos iguales, siempre habrá un detalle que diferencie uno del otro.

En cuanto a la técnica de la decoración de estos huevos de avestruz de Villaricos Luis Siret (1907), su primer excavador, ya diferencia dos técnicas diferentes, pintadas y "grabados". "La superficie del huevo está decorada con pinturas o grabados. Los grabados han sido producidos, de forma intencional o accidental, por efecto corrosivo del agua sobre las cascaras pintadas formando el relieve la parte cubierta por la pintura" (Astruch 1951: 126). Esta misma autora, que estudió y sistematizó el trabajo de Siret, añadió lo siguiente:

"En Villaricos encontramos cáscaras donde los motivos decorativos están coloreados con una pintura espesa y pulverulenta, pero, en la mayor parte, ha desaparecido dejando una especie de rastro, un relieve ínfimo que si no se ve muy de cerca se puede tomar por un grabado (...). Las últimas 
observaciones que hemos podido hacer ampliamente sobre el conjunto de las cáscaras de huevos de avestruz de Villaricos nos llevan a creer que la pequeñísima diferencia de nivel correspondiente a la decoración que aparece en las superficies de algunas cáscaras y gracias al cual, aun cuando la pintura ha desaparecido, se pueda seguir la huella de su decoración (...). Debemos, pues, pensar que el pseudograbado es cosa accidental e imprevisible y que ha podido ocurrir poco o mucho tiempo después de la ejecución del dibujo, bajo la influencia combinada de la naturaleza química de la pintura y de su exposición a determinadas condiciones atmosféricas" (Astruch 1951: 125-127).

En el estudio que hizo Miriam Astruch sobre los huevos de avestruz encontrados en la necrópolis púnica de Puig des Molins en Ibiza también hizo la siguiente observación sobre un cascarón de tipo y cronología similar a las de Villaricos: "Sur cette coquille on voit à la fois des parties peintes et des parties où la peinture a laissé une trace plastique" (Astruch 1957: 96-97).

Pero ni Siret, ni Astruch hacen referencia a la naturaleza y composición de esa extraña pintura espesa que produce este efecto sobre la superficie de los cascarones de los huevos de avestruz. La cronología que dan ambos investigadores a esta necrópolis va del siglo VI al IV a. C. Viendo que el rastro dejado en la superficie de las cerámicas de los Ait Ouriaguel decoradas con resina de lentisco, una vez que esta, al ser una substancia orgánica se hubiera degradado y borrado con el tiempo, producen un efecto similar a lo observado sobre algunos de los cascarones decorados de los huevos de avestruz, nos hace pensar que estos podrían haber sido decorados con la misma substancia resinosa, encontrándonos así con un claro antecedente de este tipo de técnica de decoración que aunque hoy en día está en plena regresión restringida a una pequeña porción del Rif así como a pequeñas áreas de Túnez y Argelia (Nedroma). Anteriormente su área de difusión fue mucho mayor siendo sustituida progresivamente por los pigmentos de origen mineral más estables y duraderos.
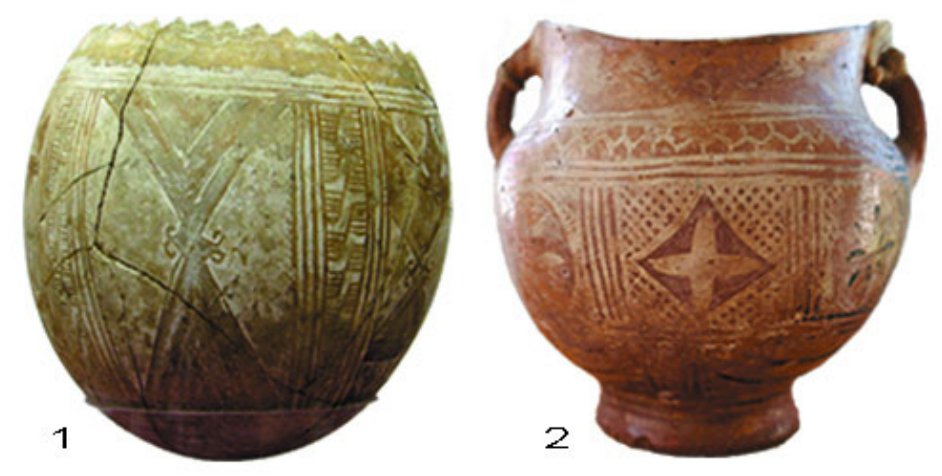

1. Huevo de avestruz. Necrópolis fenicio-púnica, VI-IV a. C.

2. Vaso de pico de pájaro. Tribu Aït Ouriaghel, primera mitad siglo $\mathrm{XX}$.

Hay que tener en cuenta también la coincidencia del área de distribución de esta técnica de decoración sobre cerámica, la franja costera mediterránea del Magreb coincide con el mundo púnico y el claro origen africano de los huevos de avestruz que están presentes en gran cantidad de enterramientos en necrópolis del ámbito púnico e ibérico.

Otro posible antecedente y origen de la técnica de la decoración con resina de lentisco podría estar en una serie de ánforas decoradas, halladas en la necrópolis ibérica de Tutugi (La Galera) y también en la de Baria (Villaricos), algunas de ellas coetáneas de los huevos de avestruz. En ellas la decoración, sin que los que publicaron estas piezas hicieran referencia a la naturaleza del pigmento utilizado, se realiza después de dar una capa de engobe claro a toda la vasija y también en ella se adivina la decoración por el rastro que ha dejado esta sobre la superficie de la vasija al igual que ocurre en las cerámicas de los Ait Ouriaghel

Está claro que la técnica en la decoración utilizada en estas ánforas es totalmente diferente y contrasta vivamente con la de las vasijas coetáneas púnicas o ibéricas decoradas con pigmentos minerales y que a veces aparecen juntas en los mismos enterramientos. En estas se ve claro que la parte de la vasija que no estaba protegida por la decoración sufre un oscurecimiento debido a la oxidación y una degradación que llega hasta hacer desaparecer el engobe, quedando este solo protegido por los trazos de la 
verdadera decoración, pero desaparecida esta, bastante tiempo después por su naturaleza orgánica, aparece el tono más claro del engobe dando al dibujo un aspecto de la decoración en negativo.

En estas ánforas, de claro origen púnico al igual que los citados huevos de avestruz decorados, se da la similitud, aparte de la técnica de decoración, que es exclusivamente geométrica ocupando prácticamente la totalidad de la vasija, coincidiendo con el horror vacui de las cerámicas de los Ait Ouriaghel, Esta decoración se compone de una serie de bandas horizontales de anchura y decoración diferentes y las de más anchura, que suelen ocupar la parte central de la vasija, a su vez dividida a modo de metopas separadas por triglifos o trazos de varias líneas verticales.

Las ánforas que aparecen decoradas en estas necrópolis del sur de España pertenecen a un tipo que es corriente en los yacimientos arqueológicos, tanto de hábitat como necrópolis, del ámbito púnico de los siglos $\mathrm{VI}$ y V a. C. en todo el mediterráneo como vasijas utilizadas para el transporte o almacenamiento tanto de líquidos como de alimentos, modelo que pronto fue copiado y asimilado por la cultura ibérica, pero por ser de uso común generalmente no aparecen decoradas. Al parecer, las ánforas decoradas no tuvieron ese uso.

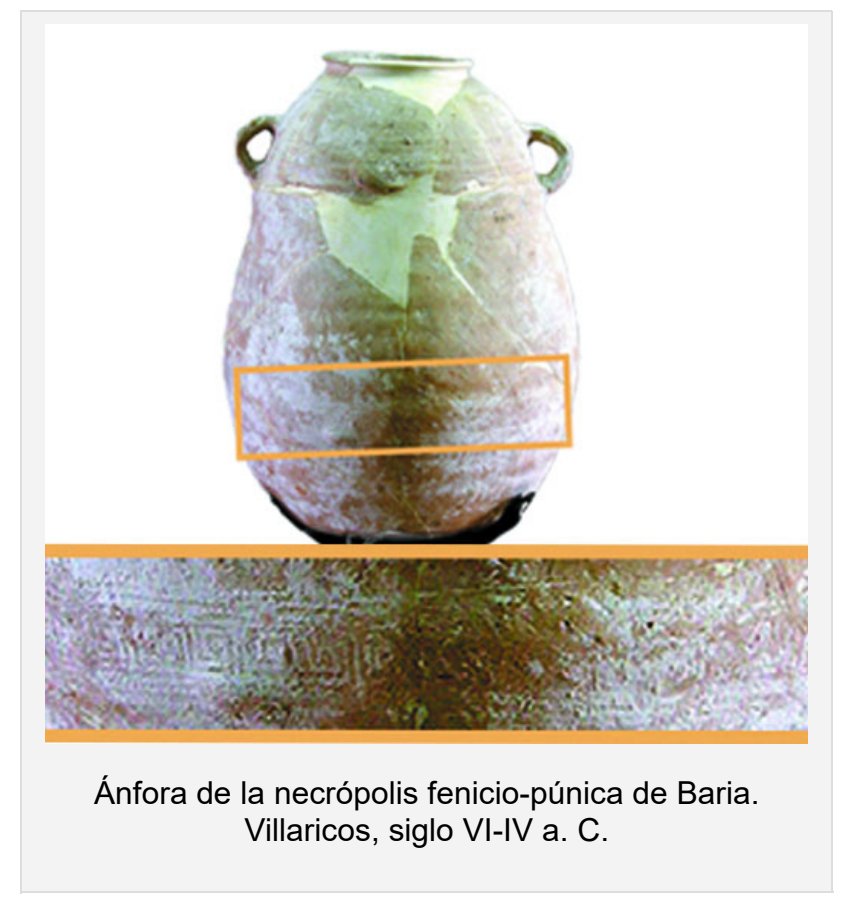

En los enterramientos de esa época, sobre todo en los de personajes de una cierta categoría, se inhumaban con sus pertenencias más valiosas y apreciadas, armas, joyas, cerámicas de importación como la cerámica ática etc. Lo exótico de su decoración y el encontrarse formando parte de un ajuar funerario, contrastando su decoración con la del resto de vasijas autóctonas, hace pensar que estas ánforas fueron objetos de importación apreciadas, al igual que los huevos de avestruz, y como estos, eran utilizados tras la defunción con un fin votivo o ceremonial. Teniendo estos huevos de avestruz un claro origen africano y por la coincidencia en estas ánforas de la misma técnica y motivos decorativos, nos haría pensar, en concreto para esta técnica de decoración, un origen de procedencia común púnico bereber. Estaríamos en el antecedente más antiguo de la aplicación de esta técnica decorativa sobre cerámica que se ha seguido utilizando sobre el mismo territorio norteafricano hasta nuestros días.

\section{Conclusiones: hacia el futuro}

En el último tercio del pasado siglo el mundo rural rifeño empieza a sufrir una paulatina pero continua transformación, en primer lugar, con la masiva emigración a Europa de los hombres y con el posterior reagrupamiento familiar en sus lugares de trabajo con la occidentalización, en parte, de sus costumbres sociales y materiales. Por otra parte, la emigración a los núcleos urbanos, en plena expansión, periféricos al Rif, Tánger, Tetuán, Fez, Nador, o más lejanos como Casablanca y Rabat que atraen a los rifeños a buscar trabajo, sobre todo las mujeres en el sector del trabajo de hogar.

Después de iniciarse este siglo, potenciado también por el terremoto de Al Hoceima, en 2002, que 
arruinó todas las casas de adobe del medio rural, se puso en marcha por parte del gobierno marroquí un plan de reconstrucción que afectó a todo el Rif, se mejoraron los accesos y vías de comunicación, se realizó el tendido eléctrico en gran parte del país y se creó la red de agua potable. Todo esto unido a la lenta pero progresiva alfabetización en el medio rural, sobre todo en las mujeres, y al progresivo acceso a la comunicación, televisión y telefonía móvil, hace que los jóvenes se sientan cada vez más atraídos por la modernidad y que se experimente una total ruptura generacional.

En el caso de la cerámica rifeña, tradición heredada secularmente de madres a hijas, se rompe totalmente. Con la progresiva modernidad, en el hogar aparecen nuevos materiales, ollas de aluminio y acero inoxidable, más ligeras, menos frágiles y fáciles de limpiar, la olla exprés, vajillas made in China ligeras, económicas, garrafas de plástico, que no se rompen si se caen y pesan muchísimo menos cuando van a la fuente a por agua, etc. $Y$ como decae su uso, la cerámica tradicional milenaria desaparece y solo algunas pocas alfareras, mujeres ya muy mayores y sin relevo generacional, realizan algunas piezas por encargo dirigidas al coleccionismo.

La tribu de Beni Said con su centro de Ifran Ali es la única que su cerámica sigue con buena salud, con la arcilla de sus canteras sus mujeres realizan una cerámica de color rojo, la única decorada con decoración cardial y motivos incisos y la más apta para cocinar al fuego de todo el Rif, sus ollas y marmitas, "tagin" se pueden comprar en casi todos los puestos de carretera en todo Marruecos con gran aceptación.

Otra tribu, Los Beni Mesguilda, en sus centros de Slit y Tarfania, bastantes mujeres siguen haciendo cerámica de forma tradicional, modelada, con engobe y decorada con pigmentos minerales, pero ya fuera de uso y destinada al turismo, coleccionismo y satisfacer la demanda de los bazares de los centros turísticos de Fez, Marrakech y de algunas otras ciudades. Las alfareras de esta tribu, aunque han guardado la técnica de fabricación tradicional, no han conservado, en parte, las formas y la decoración, adaptándolas a las demandas comerciales, saliéndose así, casi por completo, del canon de su tribu, perdiendo autenticidad y la memoria cultural.

En la provincia de Al Hoceima en la aldea de Idardouchen una asociación ha creado un centro para intentar mantener la rica cerámica de los Ait Ouriaghel, una de las de mayor personalidad del Rif. Realizan cerámicas decorativas y aunque algunas de sus piezas se salen del canon de la tribu, nuevos diseños, utilización del torno y cocción en hornos eléctricos, aunque mantienen su decoración tradicional y ancestral a base de pigmentos vegetales, la resina de lentisco.

Debido al momento en el que empezamos a realizar nuestras estancias en el terreno, aún tuvimos la fortuna de llegar a tiempo de convivir, en los primeros años de comenzar nuestro trabajo de campo, con una generación de alfareras que iban a ser las últimas alfareras de una cultura ancestral. A nuestra llegada a sus casas era como si el mundo se hubiera detenido en el tiempo. Las viviendas carecían de agua corriente, de electricidad, los patios eran de tierra batida. Los tejados de las casas eran de paja, las mujeres iban a la fuente a por agua con sus cantaros de barro, cocinaban con sus anafes y sus ollas, batían la leche con sus mantequeras, amasaban el pan con sus platos de amasar, todo en barro modeladas por ellas mismas. Todas estas piezas cerámicas poco se distinguirían de las de los restos que encontramos al excavar un poblado de los Millares, árgarico o cualquier otro del bronce. Pero, aunque próximas en distancia y la influencia que sin duda tuvo que haber entre estas culturas y sus vecinas rifeñas del otro lado del estrecho en tiempos pasados, dado el dilatado espacio de tiempo transcurrido, más de tres mil años, nos parece asombrosa la pervivencia de esta cerámica.

Otra posibilidad es pensar en que sea una cerámica autóctona convergente, mismo ambiente geográfico, misma técnica y mismos usos, generan formas similares. La cuestión es que la cerámica rifeña, sea por influencia o sea por convergencia, ha llegado hasta nuestros días comportándose como si fuera un fósil viviente. 


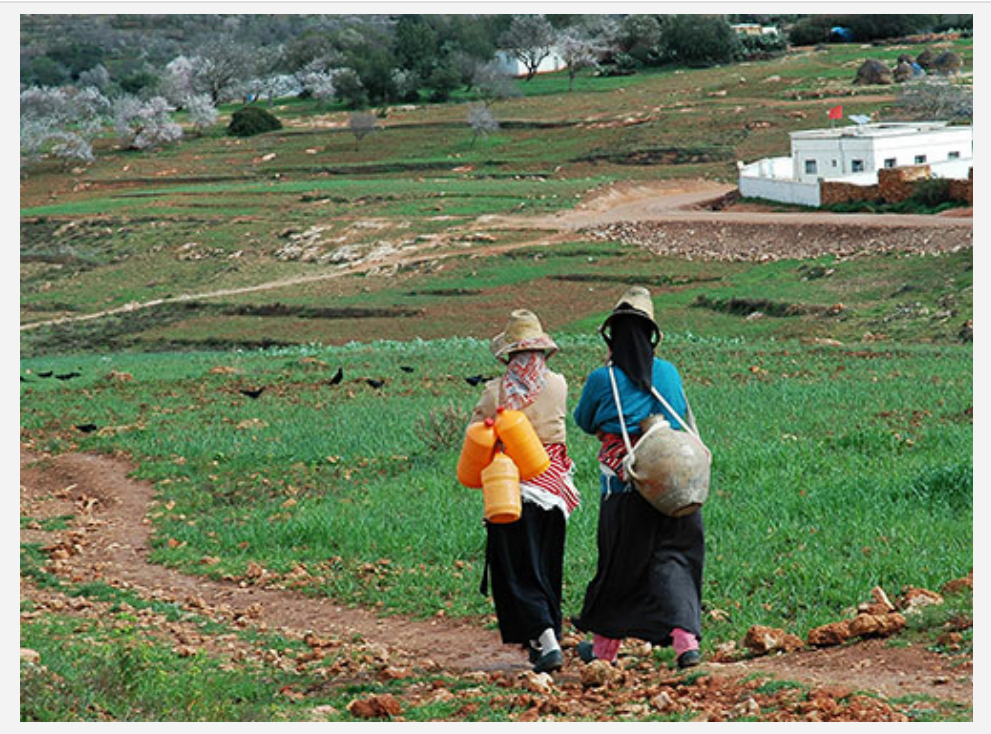

Mujeres camino de la fuente, tribu Bocoya.

Cantaro y envases de plástico comparten el mismo uso a finales del siglo XX; pero en el siglo XXI el envase de plástico se ha impuesto ya.

Se puede decir que en el Rif la cerámica, sobre todo la de la vertiente mediterránea, ha pasado de las cerámicas de la cultura de la edad del bronce a la cultura del plástico sin culturas intermedias. El futuro, siempre incierto, podría concretarse en lo que se refiere a la cerámica rifeña en forma de pregunta ¿Qué posibilidades tiene de sobrevivir de cara al futuro sin la función pragmática que las mantuvo en uso hasta llegar aquí y sin la atribución de un valor patrimonial añadido?

\section{Notas}

Todas las fotografías han sido realizadas por los autores del artículo, María José Matos y Jorge Wagner.

\section{Bibliografía}

Alcacer Grau, José

1945 "Dos estaciones argáricas en la región levantina", Archivo de prehistoria levantina (Valencia), vol. II: 151-164.

Almagro Basch, Martín

1967 “Dos ánforas pintadas de Villaricos”, Rivista di estudi Liguri (Italia), n 33: 345-353.

Aranegui Gascó, Carmen

1987 Historia de la cerámica valenciana. Paterna, Vicente García Editores.

Astruc, Miriam

1951 "La necrópolis de Villaricos", Comisaria General de excavaciones arqueológicas: Informes y memorias (Madrid), $\mathrm{n}^{\circ} 25:$ 87-188.

1957 "Exotisme et localisme. Étude sur les coquilles d'oeufs d'autruche decorées d'lbiza", Archivo de prehistoria levantina (Valencia), vol. VI: 47-112.

\section{Bazin}

2011 "Étude sur le tatouage dans la regence de Tunis", en Les Tatouages dans Afrique du nord: contribution à la recherche de l'origine et de la signification des tatouages pratiqué en Tunisie, Algérie et au Maroc. Casablanca, Editions Frontispice: 158-171. 
Bernabó Brea, Luigi

1954 "La Sicilia prehistórica y sus relaciones con Oriente y con la Península ibérica", Ampurias (Madrid), no 15-16: 137-235.

Bertholon

2011 "Origines néolithiques et mycéniennes de tatouages des populations du nord de I'Afrique", en Les tatouges en Afrique du nord: contribution à la recherche de l'origine et de la signification des tatouages pratiqué en Tunisie, Algérie et au Maroc. Casablanca, Editions Frontispice: 6-33.

Borras, Carlos

2000 Cerámica modelada y decorada del Magreb al Aqsa. Barcelona, Universitat de Barcelona.

Cabré, Juan (y Federico de Motos)

1920 "La necrópolis ibérica de Tutugi, Galera", Comisaria General de excavaciones arqueológicas: Informes y memorias (Madrid), $\mathrm{n}^{\circ} 25:$ 22-42.

Camps, Gabriel

1962 Aux origines de la Berbérie. Monuments et rites funéraires protohistoriques. París, Arts et Métiers Grafiques.

Elvira Barba, Miguel Ángel

1979 "Aproximación al estilo florido o rico de la cerámica de Liria", Archivo español de Arqueología (Madrid), vol. 52, n 139-140: 215.

García Bellido, Antonio

1954 Historia de España, España prerromana. Madrid, Espasa-Calpe.

Guichard, Pierre

2015 Par la main des femmes. La poterie modelée du Maghreb. Lyon, Publications de la Maison de I'Orient et de la Mediterranée.

Herber, J.

2011 "Le tatouage au Maroc", en Les tatouges en Afrique du nord: contribution à la recherche de l'origine et de la signification des tatouages pratiqué en Tunisie, Algérie et au Maroc. Casablanca, Editions Frontispice: $209-476$.

Lipinsky, Edward

1972 Tanit et Ba'a Hammon. Mayence, Zabern.

1995 Dieux et déesses de l'univers phenicien et punique. Louvain, Peeters Publishers.

Lopez Castro, José Luis

2014 "El comercio en Baria durante el siglo V a. C a través del registro ánforico", Treballs del Museu Arqueologic d'Eivissa e Formentera (Ibiza), nº 72: 343-352.

Luquet, Armand

1964 "La cerámique préromaine de Banasa", Bulletin d'archeologie marocaine (Casablanca), tomo V: 117-144.

Makilam

1999 Signes et rituels Magiques des Femmes Kabiles. Aix-en-Provence, Édisud.

Maluquer de Motes, Jordi

1957 “De metalurgia Tartesia: El bronce Carriazo”, Zephyrus (Salamanca), n VIII: 157-168.

Mata Carriazo, Juan de

1973 Tartessos y el Carambolo: Investigaciones arqueológicas sobre la protohistoria de la baja Andalucía. Madrid, Dirección General de Bellas Artes, Ministerio de Educación y Ciencia.

Matos, María José (y Jorge Wagner)

2013 La simbología en la cerámica femenina rifeña. Villarreal, Ajuntament de Vila-Real.

Moreau, Jean Bernard 
1951 Les Grands Symboles Mediterranéens dans la poterie Algérienne. Alger, Les Éditions a Libre Ouvert.

Moret, Pierre

1989 "Les 'araignées d'eau' de la ceramique peinte iberique", Mélanges de la casa de Velazquez (París), tomo XXV: 4-29.

Olaria Puyoles, Carmen Rosa

1974 “A propósito de dos ánforas pintadas de Villaricos", Pyrenae (Barcelona), tomo VIII: 159-166.

Ramón Burillo, José A.

1987 La alfarería del Rif. Tánger,

http://www.tifraznarif.net/pdf/livres/Livres\%20esp/LA\%20ALFARERA\%20DEL\%20RIF.pdf.

Santos Moro, Francisco de

1991 Cerámica de Marruecos. Madrid, Museo Nacional de Etnología.

Siret, Luis

1907 Villaricos y Herrerías, antigüedades púnicas, romanas, visigodas y árabes. Almería, Arraez Editores.

Vanderbroek, Paul

2000 Azetta, L'art des femmes berèberes. Bruxelles, Ludion Gand-Flammarion, Palais des Beaux-Arts.

Vazquez Hoyos, Ana María

1995 "A propósito de la serpiente en las cerámicas ibéricas de Elche", en Actas del XXIII Congreso Nacional de Arqueologia (Elche).

https://www2.uned.es/geo-1-historia-antigua-universal/PDF/SERPIENTE_ELCHE_PDF.pdf.

Vossen, Rüdiguer

1990 Reisen zu Marokkos töpfern. Hamburg, Herstellung Chistians Druckerei.

Vossen, Rüdiguer (y Ebert Wilhelm)

1986 Marokkanische Töpferai. Bonn, Rudolf Habelt GmbH.

Wagner, Jorge (y María José Matos)

2009 Cerámica rifeña, el barro femenino. Valencia, Museo Nacional de Cerámica y Artes Suntuarias González Martí. 